University of Louisville

ThinkIR: The University of Louisville's Institutional Repository

8-2006

\title{
Immigration, assimilation, and language : a case study of ESL programs in Louisville, Kentucky.
}

Korey David McMurtrey

University of Louisville

Follow this and additional works at: https://ir.library.louisville.edu/etd

\section{Recommended Citation}

McMurtrey, Korey David, "Immigration, assimilation, and language : a case study of ESL programs in Louisville, Kentucky." (2006). Electronic Theses and Dissertations. Paper 954.

https://doi.org/10.18297/etd/954

This Master's Thesis is brought to you for free and open access by ThinkIR: The University of Louisville's Institutional Repository. It has been accepted for inclusion in Electronic Theses and Dissertations by an authorized administrator of ThinkIR: The University of Louisville's Institutional Repository. This title appears here courtesy of the author, who has retained all other copyrights. For more information, please contact thinkir@louisville.edu. 
IMMIGRATION, ASSIMILATION, AND LANGUAGE: A CASE STUDY OF ESL PROGRAMS IN LOUISVILLE, KY

\author{
By \\ Korey David McMurtrey \\ B.A., Transylvania University, 2004
}

\begin{abstract}
A Thesis
Submitted to the Faculty of the Graduate School of the University of Louisville In Partial Fulfillment of the Requirements

For the Degree of
\end{abstract}

Master of Arts

Department of Sociology

University of Louisville

Louisville, Kentucky

August 2006 
IMMIGRATION, ASSIMILATION, AND LANGUAGE: A CASE STUDY OF ESL PROGRAMS IN LOUISVILLE, KY

\author{
By
}

Korey David McMurtrey

B.A., Transylvania University, 2004

A Thesis Approved on

May 18, 2006

by the following Thesis Committee:

Thesis Director 


\section{ACKNOWLEDGMENTS}

I would like to thank my committee chair, Dr. Clarence Talley, for his guidance and assistance on this project. I would also like to thank the other two committee members, Dr. Cynthia Negrey and Dr. Regina Roebuck, for their comments and contributions to my research paper. I would also like to thank my family in Maysville for supporting me through my many years of school. Lastly, I would like to express my thanks to my girlfriend, Allison, for her extreme understanding and patience during this project. 


\title{
ABSTRACT \\ IMMIGRATION, ASSIMILATION, AND LANGUAGE: A CASE STUDY OF ESL PROGRAMS IN LOUISVILLE, KY
}

\author{
Korey David McMurtrey
}

August 4, 2006

This thesis examined the structure and processes of several different organizations that offer English as a Second Language (ESL) classes in one Kentucky county. The purpose of the study was to analyze the structure of the organizations, and then analyze how the structure affects their approach to teaching ESL. There were three expectations going into this study: the ESL programs would be segregated and distinct from one another, they would be challenged to teach a diverse clientele, and the services would be strongly student-oriented. Semi-structured interviews were conducted with six program coordinators and two teachers across six different organizations. The findings revealed that although the programs do operate independently, they are much more connected than initially expected. Due to recent trends in immigration and assimilation patterns, the ESL programs teach classes holistically, based on the needs of a diverse student population. 


\section{TABLE OF CONTENTS}

\section{PAGE}

ACKNOWLEDGEMENTS iii

ABSTRACT iv

\section{CHAPTER}

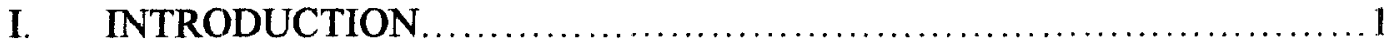

II. IMMIGRATION AND IMMIGRANTS ..............................

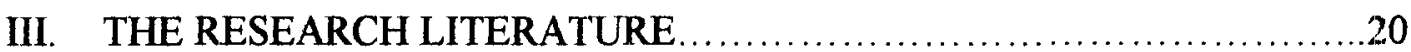

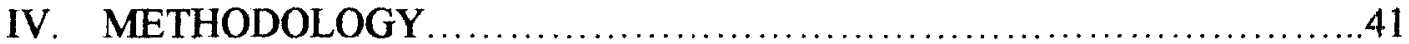

V. FINDINGS: ORGANIZATIONAL STRUCTURE AND CLASSROOM DYNAMICS

VI. FINDINGS: THE PROCESS OF TEACHING ESL ........................66

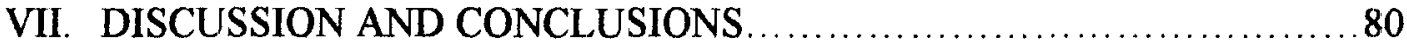

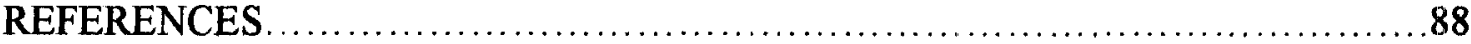

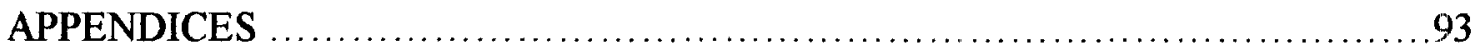

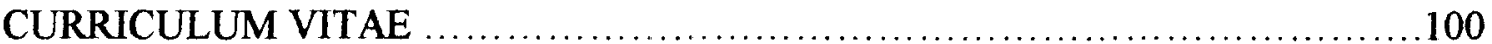




\section{CHAPTER I}

\section{INTRODUCTION}

For the thousands of immigrants who come to the United States each year, one of the first steps often necessary for their success is learning English. Mastering English language skills eases an immigrant or refugee's transition into U.S. society. One of the benefits of English language skills is to allow immigrants and refugees to have easier access to social services, health care, and the education system. English language skills also provide immigrants and refugees better chances of gaining employment and advancing in their jobs. Alternatively, a lack of English skills can lead to stressful situations as people adapt to a new and unfamiliar culture. A lack of English skills makes even routine tasks, such as banking, shopping, and medical care more challenging.

The perception is that English as a Second Language (ESL) programs are, for the most part, not cohesively organized or consistent in their teaching approach. Unlike some other countries, the U.S. does not have a cohesive, federally funded ESL program. Australia, for example, has had a stable, federally funded ESL settlement program for new adult immigrants for over fifty years (Burns 2003). No program of this sort exists in the U.S., where most ESL programs are run by a mix of local governmental and nongovernmental organizations. Local non-profit organizations and church or faith-based organizations offer many of the ESL classes. Also, educational institutions such as public school systems and community college systems usually offer ESL classes to the 
adult population. Organizations are either privately funded or supported by an array of local, state, and foundation grant money. These organizations typically have minimal guidelines or influence from a national or federal source.

The structure and quality of these classes varies greatly depending on such factors as region of the country, how the organization is funded, and the requirements for attending English classes. These varied programs therefore provide many different, and potentially unequal, opportunities for immigrants and refugees to learn English. Organizations that offer ESL classes often have disparate goals, different philosophies about how to teach English and why learning English is important, and different outcomes in terms of what happens to the immigrants once they leave the programs.

The students that attend ESL classes come from widely varying backgrounds. "The members of this population have varying degrees of English proficiency, with skills ranging from complete fluency to virtually no knowledge of English" (Kim et al. 1997:1). Students range across all age groups, dozens of countries of origin, and a wide variety of professional and educational backgrounds. ESL programs increasingly must serve students from different cultures due to changes in immigration patterns. While $68 \%$ of immigrants came from Europe and Canada in 1951, 76\% of immigrants arrived from Latin American and Asian countries by 2000 (Aguirre and Turner 2004). Students take classes that are filled with immigrants and refugees with very different experiences, native languages, English abilities, and motivations and goals for learning English.

The present study seeks to understand the structure and processes of several organizations in one Kentucky county that offer ESL classes. The primary aim is to analyze the structure of these organizations, and then analyze how the structure affects 
their approach to teaching ESL. This study is important because few studies have attempted to analyze the structure and processes of widely varying ESL programs in one U.S. city. Most studies have examined teaching strategies (Holt 1995; Shank and Terrill 1995), the goals, motivations, and needs of the immigrant students (Crandall and Shephard 2004; Fennelly and Palasz. 2003), or characteristics of specific subgroups of ESL students (Buttaro and King 2001; Warriner 2004; Weinstein-Shr 1993). Very few studies perform a program evaluation of the philosophies, strategies, and goals of several varied programs operating within the same city. ESL programs in the present study are likely to be fragmented and distinct from each other, with different sets of goals and teaching philosophies that lead to differing and sometimes ineffective classroom environments for the students.

Few studies have compared and contrasted the structure of several different organizations and the implication of organizational forms for the delivery of ESL services to the adult community of immigrants. Several studies have reported on what they found to be effective teaching strategies. These studies have implications for how ESL programs in the U.S. can or should be run. Nolan (2001), in describing one exemplary ESL program based in Central America, argues that U.S. programs could learn a great deal by emulating the success of the one very successful program outlined in his study. Nolan advocates the practicality of applying a theoretical approach to English language learning, so that the curriculum can be continuously fine-tuned and upgraded. He notes that a strict adherence to a particular teaching philosophy is largely absent from U.S. programs. This relates to one goal of the current study, which is to determine whether or 
not ESL programs in one county have an over-arching teaching philosophy, and how this affects the course curriculum and teaching practices.

Similarly, several studies report on the effectiveness of specific teaching strategies, such as the use of journal writing as a tool for English learning and reflection (Kim 2005; Orem 2001). These authors argue that journal writing can be an effective teaching tool in certain situations, as it allows students to practice writing English correctly. It also provides a meaningful context in which the students can practice their skills. However, these studies largely fail to examine the fractured, disorganized state of ESL education as it exists in the U.S. Many studies also examine specific sub-groups of ESL students, how well they cope with ESL classes, and what special needs they might have. Some examples of this type of study include examining Chinese students in the United Kingdom (Berry and Williams 2004), the special needs of Hispanic female students (Buttaro 2001), and Russians, Somalis, and Hmong in the Midwest U.S. (Fennelly and Palasz 2003). These types of studies provide a great deal of information on particular groups of students. However, they fail to address the situation in which many ESL programs operate more or less independently of each other.

This study contributes to the literature on English as a Second Language by attempting to understand how services are provided to the adult immigrant population in one Kentucky county. The study seeks to understand the organizations that offer ESL classes and the nature of the services provided. The approach of the research is a case study of the population of organizations within the county. This study should provide some insight into the differences between programs, and how these differences affect their ability to provide ESL services. Furthermore, the results of this study suggest 
changes that could be made to the current system of ESL programs in order to improve their services.

Chapter II provides the sociohistorical background to the present study. It outlines the changes in both immigration patterns and patterns of assimilation revealed by the new assimilation theories. It is argued that ESL programs are a response to changing patterns of assimilation. Chapter III presents the research literature on ESL programs, and identifies the themes and trends that are relevant for the current study. This is followed by Chapter IV, which describes the methods used in this study. The next two chapters, Chapters V and VI, describe the findings from the interviews. These two chapters describe the organizational structure of the ESL programs and the process of teaching ESL at these organizations, respectively. Lastly, Chapter VII provides a discussion of the data and draws some conclusions for future research. 


\section{CHAPTER II}

\section{IMMIGRATION AND IMMIGRANTS}

ESL programs in the U.S. today are the result of a long history of immigration and assimilation. Immigration patterns are drastically different from patterns at the beginning of the twentieth century. Likewise, as immigration patterns have changed, so too have the patterns and theories of assimilation. The goal of this chapter is to explain the changing nature of immigration and the process of assimilation, and then demonstrate how these factors have helped shape ESL programs for adults as they exist today. As a result of changing patterns of immigration and assimilation, ESL programs have become more focused on adult learners, are culturally sensitive and client-centered, and are run by local organizations.

Immigration to the U.S. looks significantly different today compared to immigration from the late 1800 s and early $1900 \mathrm{~s}$. Theories and models of assimilation have also changed drastically over the past century. This early, "classic period" of immigration and assimilation dominated the discourse on immigration until the 1960s1970s. "Underlying all explanations of immigration of this period is the assumption of social order and social equilibrium" (Heisler 1992:625), which are often analyzed in terms of push and pull factors. The majority of today's foreign-born population is from Latin American countries. Europeans, who formed the largest number of immigrants in 
earlier periods in U.S. history, account for a significantly smaller proportion of immigrants today (Schaefer 2005).

This early period of immigration was not free from conflict. Although Europeans formed a large part of the immigrant population in the 1700 s and early 1800 s, there were also very strong anti-immigrant crusades in the latter half of the nineteenth century, as the number of immigrants from non-Protestant and non-European countries continued to grow. "The earlier immigrants, if not Anglo-Saxon, were from similar groups such as the Scandinavians, the Swiss, and the French Huguenots. These people were more experienced in democratic political practices and had a greater affinity with the dominant Anglo-Saxon culture” (2005:121). As immigrants increasingly arrived from nonProtestant and non-English speaking countries, there were increasing protests from some U.S. citizens, as well as anti-immigration legislation enacted by Congress.

From the late 1800 s to about 1921 , immigrants increasingly arrived from southern, central, and eastern European countries, although immigration from northern and western Europe remained strong. There were also significant increases in immigration from Asia, as well as Latin and Central America. "Previously little-known nationality groups now flocked to the nation's shores, establishing their ethnoreligious cultural marks. By the turn of the century, most northeastern cities would contain twothirds or more of a foreign-born population" (Parrillo 2005:98). However, the increasing diversity of immigrants in the U.S. also led to a backlash from the native population. This backlash was most strongly seen in the National Origins Quota Act of 1921. This act reduced immigration to $3 \%$ of the number of people descended from each nationality in 1910 (Parrillo 2005). This quota system remained the basis for immigration to the 
U.S. until 1965. The quota system favored white northern and western European groups, because they were more abundant in the U.S. prior to 1921. Even though immigration from countries such as Great Britain dropped off sharply, immigrants from eastern and southern Europe were severely limited in their immigration options because their national quota was set so low. After statistical manipulation by the government, $70 \%$ of the quota for the Eastern Hemisphere went to Great Britain, Ireland, and Germany (Schaefer 2005).

Despite the severe restrictions, this particular immigration policy eventually came to an end. "With few Europeans to fill expanding needs, Mexicans and Puerto Ricans would meet the demand for new labor, setting in motion a greater Hispanic migration than ever before" (Parrillo 2005:108). Due to the limits imposed by the quota system, large scale immigration from Asian countries, as well as Latin and Central America, is a relatively recent phenomenon (Oropesa and Landale 1997). As a result of decreased immigration beginning in the 1920 s, along with the presence of acculturative pressures, the U.S. population drifted towards more cultural homogeneity. The slowing of immigration during this period gave assimilation slightly more dominance as a theoretical approach over the continued presence of pluralism and group differences (Parrillo 2005).

\section{Early Theories of Assimilation}

Early assimilation theories originated with Robert Park and the Chicago School.

Park "viewed immigrant/host society patterns of interaction as unilinear movements through stages, always resulting in eventual assimilation" (Heisler 1992:626). Racial and ethnic minorities and immigrant groups would eventually be incorporated into mainstream American life, socially, economically, and politically (Wildsmith 2004). Park describes several phases immigrant groups went through as they gradually 
assimilated into the larger society. These include contact, competition and conflict, accommodation, and eventually assimilation (Cornell and Hartmann 1998). Under this general process of assimilation, unique minority identities disappear as groups integrate into the culture of the majority society. Assimilation is theorized as an inevitable, unilateral process, even though it is not necessarily viewed as easy or attainable in a short period of time. The host society does not change in this process, but the immigrants slowly become more Americanized.

Park's multi-stage race-relations cycle was further expanded upon by Milton Gordon, who specifies seven distinct stages in the assimilation process in his multidimensional dissection of assimilation. The different types of assimilation are cultural assimilation (acculturation), structural, marital, identification, attitudereceptional, behavioral-receptional, and civic assimilation (Aguirre and Turner 2004). He differentiates between acculturation, where immigrants adopt the cultural patterns of the dominant group, and structural assimilation, where members of the immigrant and dominant groups develop primary-group relationships (South et al. 2005). Unlike many of his predecessors, including Park, Gordon does not view assimilation as the inevitable outcome of interaction between immigrants and the host society (Heisler 1992). However, once structural assimilation is achieved, Gordon argues that all other types of assimilation will necessarily follow. Gordon's theory still suffers from the major limitation of traditional assimilation theories; he focuses almost entirely on the immigrant's ability to adjust, while the host society remains static and unchanged. 


\section{Recent Immigration and Assimilation Patterns}

The 1965 Immigration and Naturalization Act was the catalyst for the new phase of immigration and the compositional change of the immigrant population. However, the causal effects of this act "have been exaggerated, and its most important consequences, such as the removal of barriers to immigrants from Asian and African countries, were largely unintended" (Rumbaut 1994:588). Nonetheless, the 1965 law did influence migration decisions and serves as the key context for the reception of new waves of immigrants. Many government officials at the time expected to see an increase in European immigration. However, 'push' factors to migrate to the U.S. in other parts of the world had become much stronger. European migration was quickly surpassed by Latin American and Asian immigration (Parrillo 2005). While the drastic change in the national origin of immigrants was an unintended consequence of the 1965 Immigration Act, the repeal of the quota system provided more opportunities for immigrants to move to the U.S.

The primary goals of the 1965 Immigration Act were to reunite families and protect the American labor market. Thus, in addition to eliminating the quota system, the act allowed family members of U.S. citizens to enter without restriction. It also increased the number of visas that were issued for professions and occupations that were in short supply. These policy changes were responsible for significant changes in both the composition of arriving immigrant groups and their occupational skill levels over the years (Aguirre and Turner 2004). Although immigration increased by one-third after passage of the act, the more significant change was the composition of immigration. 
Schaefer (2005) estimates that immigrants from Latin America and Asia combined to make up $81 \%$ of legal immigrants who were admitted to the U.S. between 1981 and 2000. Similarly, Aguirre and Turner (2004) show that while in 1951,68\% of immigrants came from Europe and Canada, by $2000,51 \%$ of immigrants were from Latin America and the Caribbean and $25 \%$ of immigrants were from Asian countries. Major Asian sources of immigration include China, the Philippines, Vietnam, India, and Korea, while major Latin American and Caribbean sources of immigration include Mexico, the Dominican Republic, and El Salvador (Oropesa and Landale 1997). The nature and composition of immigration has changed dramatically.

There are some other important differences between the 'new' immigration of the last few decades of the twentieth century and the 'old' immigration of the early twentieth century. Since World War II, legal immigration has been more likely to result from family reunification processes, rather than economic cycles and intentional recruitment. Furthermore, "while in the first decades of the century $67 \%$ of all immigrants were men, since 1941 the majority - 55\% - have been women" (Rumbaut 1994:590). Unlike many flows of immigrants prior to World War II, more recent immigration features an increasing number of political refugees and asylees, highly skilled professionals, and undocumented laborers. The literature supports the common assumption that immigrants today are a highly diverse group, coming from many different parts of the world.

Changes in immigration patterns are not simply a direct result of the 1965 Immigration Act. Rather, "the size and source of new immigrant communities in the United States today is directly if variously related to the history of American military, political, economic, and cultural involvement and intervention in the sending countries, 
and to the linkages...that open a surprising variety of legal and illegal migration pathways" (Rumbaut 1994:588). As a result of this complex series of linkages, new waves of immigrants increasingly arrive from countries with different languages, cultures, and non-western practices. Most importantly, many of these groups are somewhat unfamiliar with democratic political practices, and are culturally and linguistically distant from the dominant Anglo-Saxon culture in the U.S.

The recency of immigration also carries implications for the socioeconomic outcomes of immigrants and refugees. Recently arrived immigrants should have a more difficult time than others, given how difficult it is to adjust to a new society. For example, Asian-born immigrant families are twice as likely as native-born Asian families to live in poverty, although this is a disadvantage that disappears over time (Oropesa and Landale 1997). Nonetheless, as difficult as adjusting to a new society can be, learning English is one of the most important steps an immigrant can take to advance in the U.S., economically and socially.

How much do new immigrant groups conform to their new society? Among the broad categories of Asian, Latino, and European immigrants, from 1983 to 2000, European immigrants had the highest rate of naturalization (Aguirre and Turner 2004). This statistic seems to be consistent with the notion that immigration policies still favor European immigrants. However, since Asians and Latinos tend to reside in areas where they make up the majority population, they may have less interest in becoming natural citizens. "The structural accommodation of Asians and Latinos in the United States may facilitate their participation in, but not their absorption into, mainstream social institutions" (2004:253). For example, the Cuban community in Miami grew relatively 
quickly. As a result, Cubans in that community have less need to adapt to the majority culture, and also have less need to learn the English language.

\section{New Theories of Assimilation}

Just as immigration patterns have changed over the last century, so too have theories about assimilation. Recent research branches in two different directions, extending and reconceptualizing the classic assimilation framework. One perspective supports and extends the general assimilation framework, while the other perspective proposes a new theory called segmented assimilation (Wildsmith 2004). The first explanation tries to expand and fill in the gaps in the assimilation theory made famous by Park and Gordon, while the latter explanation tries to describe assimilation that can go in different directions based on different circumstances.

Alba and Nee (1997) try to extend the traditional assimilation framework, instead of defining assimilation as one group becoming like another. They argue that assimilation can also occur "by changes in two (or more) groups that shrink the differences and distance between them -- group convergence, in other words" (1997:834). Assimilation is commonly portrayed as a unidirectional process in which ethnic minorities lose their unique qualities and become copies of the ethnic majority (Alba 1999). This new conceptualization allows for changes in the majority population as well as ethnic minorities. The classic assimilation theories assume the majority population is relatively homogeneous. However, assimilation also occurs unintentionally, "as the often unintended cumulative by-product of choices made by individuals seeking to take advantage of opportunities to improve their social situation" (1999:8). For example, socially mobile European ethnics may leave working class neighborhoods for middle 
class and more ethnically diverse suburbs, thus raising their children in a different environment.

The second theory, segmented assimilation, differs considerably from traditional frameworks of assimilation. The segmented assimilation perspective argues that there may be multiple trajectories of assimilation in different directions, partly depending on characteristics of both the ethnic minority and the majority group (Arias 2001; Portes 1995; Portes and Rumbaut 2001; Zhou 1997). Four of these characteristics are: 1) the history of the immigrant first generation; 2) the pace of acculturation among parents and children; 3) the cultural and economic barriers confronted by second-generation youth; and 4) family and community resources (Portes and Rumbaut 2001). Unlike traditional assimilation into a homogeneous majority, there may be three paths of assimilation. "One of them replicates the time-honored pattern of growing acculturation and parallel integration into the majority white middle class; a second leads straight into the opposite direction, to permanent poverty and assimilation into the underclass; a third links economic mobility with preservation of the immigrant community's solidarity" (Portes 1995:251). This perspective acknowledges that immigrant groups may be influenced by different groups, or benefit more from maintaining their ethnic identity.

Segmented assimilation places the assimilation process within the context of a society that consists of segmented and unequal parts. Within this context, an individual may experience downward assimilation into an underclass, rather than the traditional assimilation into the mainstream (Zhou 2004). A combination of individual and contextual variables influences the direction that assimilation takes (Zhou 1997). Community-level social structures, as well as the more general social and economic 
context of a society, affect individual assimilation. "For example, if ethnic communities are 'institutionally complete,' whereby ethnic institutions are rich and vibrant and reinforce the desirability of remaining within the ethnic fold, maintenance of ethnic identities at the individual level (if desired) is much more viable than if ethnic communities lack such completeness" (Arias 2001:528). Different variables affect the degree to which immigrants maintain their ethnic identities.

Examining the similarities between these two new perspectives on assimilation, Alba (1999) argues that at least the motives for assimilation are similar to past motives. The motive is "the desire to take advantage of opportunities to improve the social and material circumstances of one's life, whether this involves residential mobility to a new neighborhood or an upward occupational and educational trajectory" (1999:21). Similar to a century ago, assimilation occurs partly as a result of immigrant's desires to improve their social and economic lives. At the same time, the extent and degree of potential assimilation for members of particular groups is somewhat less clear. Some individuals see some forms of assimilation, such as learning English, as the path to greater opportunities and social mobility. As a result, some second-generation immigrants may raise their children to only speak English "in the belief that their educational life chances will be improved by their more complete mastery of the host language" (1999:21). These fundamental changes usually carry ramifications for future assimilation.

How does ESL relate to theories on assimilation and language? Immigrants in the early nineteenth century faced strong Anglo-conformity pressures, especially within the school system (Feagin and Feagin 2003; Wildsmith 2004). During older periods of immigration, there was little focus on educating adult immigrants. The focus was on 
assimilating their children in schools. Today, there are many ESL programs adults can choose from to learn English. However, they do not focus on assimilating immigrants and refugees completely into white American culture. ESL programs try to teach students the English language and American culture, while also encouraging them to maintain their own ethnic identity and culture.

In some ways, this approach resembles a return to pluralist views of ethnicity, in which ethnicity remains a powerful force among groups of immigrants and refugees (Aguirre and Turner 2004). ESL programs often try to be culturally sensitive to their students, and do not try to force American values and lifestyles on them (Buttaro and King 2001; Berry and Williams 2004). ESL programs do not try to replace their students' culture with American culture. Instead, they try to teach English to immigrants as a supplemental resource that will aid their adaptation to a new society.

ESL programs, operating as independent sites, encourage students to maintain and share their ethnic backgrounds while also learning English and U.S. culture. ESL classes inherently prompt some degree of language and cultural assimilation, while avoiding complete structural assimilation (South et al. 2005). Recent waves of immigration have been relatively large and fast (Aguirre and Turner 2004; Parrillo 2005; Schaefer 2005). For example, large numbers of Cubans that settled in Miami were able to maintain ethnic communities and avoid completely adopting the mainstream culture. Hispanics will soon be the largest subordinate racial group in the U.S. Such quick demographic changes, without strong government efforts to enforce Anglo-conformity, can turn immigrant groups into a powerful political force. 


\section{Education and Immigration}

The public school movement gathered support in the first decades of the nineteenth century. High levels of immigration put a great deal of pressure on the education system. Immigration strains the education system in three ways; language differences, volume of enrollment, and adaptation issues (Jeynes 2004). Problems arise because few new immigrants are fluent in English, heavy periods of immigration result in overcrowded schools, and it is very challenging for schools to try to assimilate immigrants into the mainstream. As a result, the American education system has traditionally been a means of socializing immigrants into acceptable Anglo-Protestant value systems. "Americanization pressures on immigrant children were often intense. Whether children were Irish, Jewish, or Italian, Anglicization was designed to ferret out non-Anglo-Protestant ways and assimilate the children to Anglo-Protestant manners, work habits, and values" (Feagin and Feagin 2003:69). Schools were designed to rid children of ethnic characteristics and mold them to closely resemble members of the dominant group. What typified these early schools was an Anglo-Saxon Eurocentric curriculum (Aguirre and Turner 2004). Even as Catholic schools and other religious institutions began to emerge, "the substance of the secular curriculum in these schools contained the core values and beliefs of the early Northern European settlers" (2004:53).

The Irish provide one example of the attempt at 'domesticating' immigrants through the school system. Thousands of Irish migrated to cities and towns in the northeastern U.S. after the Irish potato famine of the mid 1800s. "Schooling was seen as a means of integrating this 'uncouth and dangerous' element into the social fabric of American life. The inferiority of the foreigner was taken for granted" (Bowles and Gintis 
1976:28). The natural assumption was that immigrants were inferior and needed to be brought in line with American values as quickly as possible. The public school system tried to fulfill this purpose.

The social-control function of public schools remains evident today. "More recent immigrants, such as Asians and Latinos, have faced Anglo-conformity pressures similar to those experienced by earlier Irish and Italian immigrants" (Feagin and Feagin 2003:69). The debate over whether English should be the official language of the U.S. is often fought through the public school system. Despite this legacy of social control and assimilation, recent curriculum has begun to accommodate the realities of non-European immigrants. "In many instances, however, this new material is viewed as a supplement to the core white, Anglo-Saxon, middle-class thrust of the school culture and curriculum. These new materials are designed as supplements to efforts at Americanizing those who were unsuccessfully assimilated,...those who have resisted full assimilation,... and newer immigrants" (Aguirre and Turner 2004:53). Even with changes to the curriculum, the focus is still on conformity to the dominant group.

There has been a significant shift in the role of education institutions from socialization to a focus on accreditation and achievement. The increased stratification of the white collar labor force uses educational credentials to justify inequalities. As more and more immigrant and subordinate groups advance further in the education system, there is less of a focus on socialization and more of a focus on providing credentials. The heightened struggles of "minority groups tend toward an intensified disparity between the number of 'credentialed' workers and the number of high-status and rewarding jobs" (Bowles and Gintis 1976:203). Thus, it seems to some degree to be less important that 
schools Americanize immigrants, and more important that immigrants can gain accreditation, which helps with employability. One barrier that stands between immigrants and education is often language.

Immigrants' English acquisition is affected by several factors, including age at arrival, education, and length of residence in the U.S. "Immigrants who come with the intention of taking up permanent residence are more likely to acquire English than those who view themselves as sojourners" (Alba and Nee 2003:220). An immigrant group's size and degree of segregation influence the shift to English, such that larger, more segregated groups shift more slowly. The traditional view has been that by the third generation, immigrant families become speakers of English only (Portes 1995; Waters and Jimenez 2005). The three generation model of language assimilation appears to hold for today's newer immigrants as well. "The immigrant generation makes some progress but remains dominant in their native tongue, the second generation is bilingual, and the third generation speaks English only" (Waters and Jimenez 2005:110). The children of the new immigrant groups seem to assimilate at levels equivalent to previous groups. 


\section{CHAPTER III}

\section{THE RESEARCH LITERATURE}

There has been little organizationally focused research comparing and contrasting the structure, goals, and processes of ESL programs. The literature commonly assumes that adult ESL programs in the U.S. are widely scattered, distinct programs that operate largely independently of each other. Perhaps Nolan (2001) provides the best example of programs in the U.S., when he says:

"Four ESL programs available in my community are virtually indistinguishable from each other in terms of a theoretical viewpoint. They are supported by a local literacy council, local churches, or federal funding. It is possible for a resident of my community to participate in every one of the four programs because they are not scheduled in such a way as to compete for the same students" (2001:3-4).

Much research takes for granted this assumption about ESL programs in the U.S. The literature therefore ignores an analysis of the broader structure, organization, and processes of adult ESL programs in the U.S.

This literature review will discuss several themes that emerge from the literature on ESL. These themes include the challenges of teaching a diverse ESL student population, the types of teaching philosophies employed by ESL programs, and the teaching strategies used in ESL classrooms. Although much of the research is not organizationally focused, the literature does have implications for the organizational and structural nature of ESL programs. 


\section{Characteristics of ESL Students}

One of the most consistent themes in the ESL literature is that these programs must often serve an extremely diverse population. Students represent dozens of countries of origin and range in age from teenagers to senior citizens. Men and women are roughly equally represented. Wealthy and poor students learn together, just as a college graduate may learn alongside a high school dropout. If ESL students are such a diverse group, can scattered, under-funded ESL programs in the U.S. acknowledge their students' personal backgrounds, and offer classes that are most beneficial to the needs of the students? The diverse clientele of ESL programs must be taken into account when examining program organization, philosophy, and teaching strategies. Several issues are relevant when discussing the ability of an ESL program to serve a diverse population, including: sensitivity to national origin and positional demographic variables, immigrants' literacy in their native language, and how to teach English to such a diverse clientele.

\section{Student Demographics}

When designing ESL classes, organizations must take into account the demographic variables of the potential students, including both national origin and positional demographic characteristics. The national origins of ESL students vary widely. A century ago, most immigrants arrived from northern and western Europe. Since immigration reform in the 1960s, immigrants have increasingly arrived from Central America and Asia. More recently, widely divergent groups such as Russians, Bosnians, and Somali Bantu speakers have increasingly entered the U.S. (Crandall and Shephard 2004). Immigrants and refugees from different native countries have different needs and goals. For example, Russian, Somali, Hmong, and Mexican ESL students in 
the Midwest are understudied groups that have largely been overlooked by researchers. These four groups have large differences in English proficiency as a result of their different national origin groups (Fennelly and Palasz 2003).

ESL organizations must take national origin differences into consideration when designing their classes, philosophy, and goals. As shown above, there are dramatic differences in the English abilities of immigrants from different regions of the world. However, broad regional categories often mask differences based on national origin group. For example, "studies that group all Spanish-speaking individuals together ignore the differences that exist between such Latino groups as Mexicans and Cubans" (2003:96). Mexican immigrants are routinely less educated in their native country, while Cubans often come with some degree of native literacy.

Second language learners also have widely varying positional demographic characteristics such as gender and age. Several studies have explored the differences between male and female English language learners (Buttaro and King 2001; Loori 2005; Warriner 2004). For example, Hispanic women must often make cultural, linguistic, and educational adjustments in their daily lives. For these women, their success centers on the family environment, which "was the pivotal element determining academic success or failure" (Buttaro and King 2001:53). Understanding the literacy needs of women necessitates understanding the broader cultural and social needs of their families. As another example, female refugees' experiences as second language learners are "influenced and mediated by their experiences as women and as political refugees" (Warriner 2004:179). ESL programs must acknowledge existing cultural and linguistic skills possessed by women, while also assisting learners in acquiring new types of 
knowledge and skills. Just as female immigrants and refugees arrive in the U.S. with unique experiences and backgrounds, so do all immigrants arrive with unique personal histories that influence their English learning and adaptation to a new society.

ESL classes also often have students separated in age by fifty years or more. Teaching material that is appropriate and challenging for each age group in the class is a difficult challenge for ESL programs. Older immigrants often have very different needs and more limitations than their younger classmates. "Uprooted elders are in multiple jeopardy - they are, for the most part, poor, members of a minority culture, and nonEnglish speaking. The majority of this group are women, who often lack information on strategies for tapping available community services" (Weinstein-Shr 1993). For example, older Russian immigrants have more trouble acquiring English language skills than younger immigrants. "As a result of limited English fluency Russian elders may have difficulty communicating with grandchildren and others, and problems navigating the health care systern and public agencies" (Hubenthal 2004:105). Some abilities, such as speed of information processing, attention span, and memory skills decrease as people get older. Even though older adults are capable of learning English, they may learn more slowly and require more repetition than younger students (Hubenthal 2004).

\section{Literacy in the Native Language}

The second important issue with the backgrounds of immigrants is their level of literacy in their native language. Immigrants and refugees who were largely illiterate in their native country present several challenges for ESL programs. Less-literate students find ESL classes much more difficult than students with higher levels of literacy. "Many are unfamiliar with a school-like environment. Often teachers rely on printed texts, the 
use of the blackboard, and grammatical explanations, even to teach spoken English. Social stigmas associated with illiteracy may cause learners to be reluctant to admit their difficulties" (Gillespie 1994:1). The challenge of teaching students who are illiterate in their native language is further compounded when those students must be taught alongside students with greater literacy skills. Teaching English to diverse groups of students in the same classroom is a major challenge faced by many ESL programs.

A small amount of formal education in their native country also affects how students respond to ESL classes. "Early negative experiences with schooling make it difficult for students to return to programs that may mirror the structure of elementary and secondary schooling" (Skilton-Sylvester and Carlo 1998:2). Immigrant adults who are both new to English and new to literacy are the most disadvantaged. "Among immigrant adults (age 25 and over), almost a third lack a high school education - a proportion more than twice as high as among native-born residents. Over two-thirds of Mexican immigrants lack a high school education" (Wrigley and Strawn 2003:2). As a result, a small but growing number of programs have begun to also offer literacy classes in the native languages of the learners. This additional service places added strain on ESL programs to come up with extra funds, classes, and different instructors that can teach multiple languages.

The importance of an immigrant's literacy in their native language is reflected in an ongoing debate over whether ESL classes should be bilingual or English-only. Based on the available literature, it is difficult to determine whether students learning English as a second language are better off learning in a bilingual or an English-only classroom. The most prominent example of English immersion policies is in California. In 1998, 
California voters approved Proposition 227, which ended programs that used primary languages other than English for instruction (Paredes 2000). Advocates of this proposal claim that bilingual education is ineffective, and fails both to teach English to non-native speakers and does not provide a better education to these students. In this case, Englishonly instruction does not have a negative effect on the students as many had initially feared. The ESL students cope with the English-only classes, and for the most part do very well in their classes.

Some teachers feel that teaching students in English is the most important aspect of ESL education, and that the bilingual programs had too many problems to be effective. "The most effective way for students to learn a second language and to learn subject matter in that second language is to learn in the second language... rather than learn in the students' native language" (Rossell 2005:33). Although bilingual education has traditionally enjoyed a great deal of support among researchers and educators, the apparently successful implementation of English immersion programs in California, Arizona, and Massachusetts may change that perception. Despite being labeled bilingual classrooms, many English language programs are actually sheltered English immersion classes, where the classes are taught entirely in English but at a pace at which the ESL students can keep up.

There has also been a great deal of research that found that bilingual education is a better approach for ESL students. Some authors have concluded that a bilingual approach to teaching ESL students is superior because it increases measures of students' academic achievements in both English and in their native language. Rolstad et al. (2005) found bilingual approaches to be advantageous to students. They conclude that 
English-only policies that have been implemented in California, Arizona, and

Massachusetts cannot be justified. From a bilingual perspective, the native language and experiences of the students are extremely important to their potential success at learning English as a second language. One key principle is that the student's first language plays an essential role in learning a second language (Ernst-Slavit et al. 2002). Studies show that "the more the native language is academically supported, in combination with balanced second-language development, the more ESL students are able to academically achieve in the second language" (2002:118).

ESL programs also need to focus on the personal experiences each student brings to the classroom. For example, needs-based ESL programs teach English based on the specific needs of the students. "Some studies show benefits to students in holding on to their native language, whether it is used in the classroom or at home" (Miller and Endo 2004:790). Students who become bilingual have greater success at learning English, and are likely to attend classes longer than those who completely switch to English. Regardless of whether classes are true English immersion classes, it seems likely that students who continue to use their native language in some form are better off than those who do not.

\section{Teaching English to a Diverse Clientele}

Teaching English to such a diverse group of students is one of the biggest challenges of ESL programs. There is no typical adult ESL student. They differ in their "languages and cultural backgrounds, their prior educational experiences and literacy, their employment history, their English language proficiency, and their reasons for participating" (Crandall and Shephard 2004:4) in ESL classes. Some students were 
highly educated in their native country, and this previous education helps the speed at which they can learn English. Many other students are illiterate in their native language, which makes learning English even more challenging. Students also have different motivations for participating. Some immigrants want to advance in their jobs, others only seek basic English and literacy skills, and others study English in anticipation of gaining citizenship.

The literature shows that many programs are unable to provide ESL classes that can accommodate the needs of such a diverse student population. As a result, adult ESL students routinely find themselves in classes with other students that have very different needs (Crandall and Shephard 2004). For example, a well-educated man from India may be in the same class as a poor rural farmer from Mexico. Students with good oral English skills are often in the same class as students who know very little English. "This wide range of prior educational experiences and reasons for participating in adult ESL instruction requires an equally diverse range of programs. It is often difficult to design programs that are sufficiently broad or nuanced to accommodate the needs of this varied group of learners" (2004:4). Classes with varied levels of students present a difficult challenge to program coordinators and teachers. It is difficult for coordinators to provide services as diverse as the clientele because many ESL programs lack the funding and guidance necessary to meet these needs. Teachers must try to simplify lessons for lowlevel students, and also present more challenging concepts to maintain the interest of the more advanced students.

Many ESL programs focus on what is often called 'survival English,' where students attend classes in order to learn enough English to get by in their daily life. These 
programs try to fulfill the short-term needs of refugees and immigrants who are seeking enough English language skills to find entry-level employment. Some critics argue that this type of teaching approach takes a very narrow view on teaching English. Survival English "supports and enacts ideologies that devalue new immigrants and the languages they speak, confining the students...to 'dead-end' jobs with little potential for advancement or social mobility" (Warriner 2004:193). Supporters of survival English argue that it allows immigrants to quickly gain skills that are useful in their daily lives.

Despite these differences in the students, many immigrants of all backgrounds are eager to learn English. In many instances, immigrants show increases in English proficiency the longer they remain in the U.S. The eventual success of immigrants and refugees in gaining a certain level of English ability ultimately depends on many factors, including "the timing of their migration, the skills and personal characteristics that they bring with them to the United States, and the available opportunities once they are in the country" (Fennelly and Palasz 2003:120). Immigrants' and refugees' ability to adapt to a new culture depends on both external and internal factors, including the receptivity of the host culture and their personal motivation and desire to learn English (Kim 2001). Many immigrants recognize the importance of learning English. One of the main challenges is determining how best to teach English to such a diverse population.

\section{In the Classroom: Teaching Strategies}

Just as it is hard to describe a typical ESL student, it is also difficult to describe the teaching strategies used in a typical ESL classroom. Teachers use different teaching strategies depending on the skill level of their class. Teachers working in low-level English classes often utilize "beginning level learners as active participants in selecting 
topics, language, and materials" (Holt 1995). In these classes, teachers often use a variety of teaching techniques to appeal to diverse learning styles. For example, teachers have their students relate their personal experiences, frequently repeat important concepts and topics in class, and encourage the students to interact with and learn from each other. These beginning classes also use a wide variety of materials, including real-world objects, flash cards, games, pictures, and audio tapes and videos. There is a greater chance of success when "approaches, techniques, and materials are suitable for adults, are related to their real needs, and promote involvement in their own learning" (Holt 1995).

Many teachers must be aware of students with different skill levels in the same classroom. "Teachers use the term multilevel to identify any group of learners who differ from one another in one or more significant ways" (Shank and Terrill 1995). Many variables can affect the levels within a class. Due to various economic and structural constraints, some programs place learners from beginning to advanced levels in the same class. Students in the same class often speak different native languages, use different alphabets, and have widely varying demographic characteristics. The most effective way to work with a multilevel class involves extensive planning beforehand. By planning based on the needs and characteristics of the students, teachers "can use a variety of techniques and grouping strategies and a selection of self-access materials to help all learners be successful" (Shank and Terrill 1995). If teachers do not take the effort to thoroughly plan a lesson, they run the risk of teaching to the middle of the class, while frustrating the beginning students and boring the advanced students.

Community college ESL programs also face the problem of working with students at different skill levels. Crandall and Sheppard (2004) found that different levels 
of adult ESL programs at community colleges serve different purposes. "Beginning ESL courses focus on survival skills with some attention to employment. Advanced ESL courses focus on academic skills. Intermediate courses are therefore sometimes hard to define" (2004:15). They further argue that few programs have curricula that enable learners to acquire literacy and basic English skills, while also advancing to higher level classes. So although the community college ESL classes can teach students basic skills, they have trouble transitioning those low level students to more advanced classes.

\section{Non-Traditional Teaching Strategies}

In addition to regular teaching strategies employed in 'typical' ESL classes, there has also been recent research examining some non-traditional approaches to teaching English to second language learners. More specifically, some research has shown that journal writing, service learning, and film studies can be effective ESL teaching strategies. However, these are mostly only useful in very specific situations. Of these three examples, journal writing is the technique that is most applicable to almost any level ESL class, since students can spend time writing at their respective skill level. Journal writing can be used as a meaningful way to raise students' levels of engagement in the classroom (Kim 2005; Orem 2001). It helps develop second language literacy by providing students with an opportunity to practice English in a meaningful and authentic context. Kim (2005) argues that the importance of journal writing for ESL students is being at the center of a learner-centered approach to teaching English. Journal writing is seen as an important strategy where both students and teachers can share their thoughts in a meaningful way. Journal writing allows students to write about topics and problems that are of interest to them, thereby helping set the agenda for the class. 
Orem (2001) elaborates that journal writing reduces the pressure to be grammatically correct by stressing the ultimate goal of communication. As a communicative approach, students can write about topics that are meaningful to them, while not worrying about correct English grammatical structure. The goal is for students to be able to effectively communicate with native English speakers. In survival English classes, in particular, communicative journals can give students the freedom to talk about problems they are having with their job or social life. Teachers can then design future lessons around the personal needs of the students, which provide a greater impetus to learn and helps the students solve problems in their daily lives. The "knowledge that the learners had from their prior experience was the most essential and useful resource for developing new knowledge in their new language and culture" (2001:29). This reflection allows students to further develop their knowledge of their new culture.

Service learning can also be a useful teaching strategy in ESL classes, and falls closely in line with the critical approach outlined later. As a critical approach, service learning can serve as a form of empowerment for students, as they learn the value of providing services to their community. This attitude then places second language students in positions where their cultures and languages are valued. Second language students who were involved in service learning projects "tended to increase their participation in class and earn better grades; they became more excited about, and involved in, school. They also experienced increased self-confidence..." (Grassi et al. 2004:89). Therefore, service learning could be especially beneficial for second language learners as they discover their role within their community, as they work in communities that are culturally and linguistically diverse. 
Film studies can also teach greater English language competency, particularly to ESL students who plan on going to college. Pally (1998) found that ESL university students had acquired a different standard of speaking and writing English. As a potential solution, she piloted a film studies course for low-intermediate through advanced ESL students at one university. Sustained content study in a film class provides the students with an opportunity to practice reading and writing that would be required of them in a college or job setting. This focus on advanced reading and writing forms is an example of a structural approach to teaching English, as explained later. Most ESL students do not learn English for its own sake. Instead, "they learn because they must learn subject matter through the medium of the second language" (Mohan 1986: 1). However, there is a problem with Pally's work as it pertains to the current study, since she looks at students who attended or planned to attend college. One question not addressed by her research is: would film studies or a sustained content course be useful for lower-level ESL students, or for students who only want to learn survival English?

\section{Teaching Philosophies Behind ESL Programs}

Learning English as a second language is a long and difficult process. It is extremely important to determine the most effective strategy to teach English to secondlanguage learners. While conversational English may be gained in a couple of years, academic English can take anywhere from five to eleven years to develop (Ernst-Slavit et al. 2002). Similarly, the Mainstream English Language Teaching (MELT) Project concluded that "it takes an adult with native language literacy and no prior English instruction between 500 and 1,000 hours of instruction to satisfy basic needs, function on 
the job, and interact on a limited basis through English" (Crandall and Sheppard 2004:15). Acquiring enough English to enroll in a college-level program takes significantly longer. In addition, those students who are illiterate in their native language require an even greater number of instructional hours to become fluent or proficient in either English or their native language.

\section{The Communicative Approach}

There are many different approaches to teaching English as a Second Language (ESL). Orem (2001) distinguishes between several different teaching methods, including communicative, structural, and critical approaches to teaching ESL. Of the three approaches, the communicative approach is most commonly used in ESL classrooms. The goal of this approach is the effective integration of basic communication skills into each lesson. Communicative approaches are the most common today, because many programs advocate "teaching language that is used in general social and employment settings" (2001:73). This approach is often used in learner-centered programs to teach 'survival English.' The goal of these programs is for the students to be able to effectively communicate with native speakers in their new environment. While students may make grammatical or structural mistakes when speaking or writing, the importance of the classes is that the students are able to make themselves understood by others in English.

The communicative approach is commonly used because language best develops in a variety of settings that promote talk and interaction (Ernst-Slavit et al. 2002). ESL students benefit from classrooms where communication is "integral to the process of negotiating knowledge, exchanging personal experiences and thoughts, and the development of language and literacy abilities" (2002:119). The two most important 
resources language learners have are their competence in oral language and their ability to learn language for new situations. Their innate resources are a valuable attribute in a communicative classroom.

\section{Structural and Critical Approaches}

Structural approaches, on the other hand, are most often found in academic settings. This approach is often used in preparing students to take the Test of English as a Foreign Language for college admission. "The goal of successful second-language teaching in programs advocating a structural approach is control of the basic mechanics of language, for example, grammar and pronunciation" (Orem 2001:73). In these classrooms, teachers focus on correcting grammatical errors and provide the students an opportunity to practice correct language forms. These classes emphasize grammatical rules and the use of 'correct' English over simply being able to communicate.

Critical approaches view language as a means to an end. The goal in these programs is to empower students, letting them critically analyze their work and social contexts in terms of power relationships (Pennycook 1999). The goal in this approach is to "enable learners to gain some control over their social environment. Learning the language provides them with a powerful tool, but it is not an end in itself" (Orem 2001:76). Learning English allows immigrants to gain some power and control in their new environment. However, the goal in this case is not education for the sake of learning. Rather, learning English allows people to advance in their jobs, accomplish everyday tasks on their own, and gain some of the rights accorded to native citizens.

Of the three approaches, the communicative approach has the most applicability to the everyday life of a 'typical' immigrant or refugee. The benefit of being able to 
more clearly communicate with native speakers of English is a practical and useful skill for immigrants and refugees. The structural approach, by focusing on proper grammatical structure, is only practical for a limited number of ESL students who are enrolled in more advanced education classes, such as at a community college. However, the goal of critical approaches, to empower students, is often an indirect result of communicative approaches. As immigrants learn how to better communicate with native speakers, they also gain the ability to solve their own problems and improve their ability to meet everyday needs. Since basic communication is the most visible and urgent need of the immigrant population, communication is also the most common approach used in the classroom.

\section{Theory-Driven Approaches}

Another teaching approach has implications for the organization of ESL programs in the U.S. and emerges from the comparative literature on ESL. As mentioned earlier, Nolan (2001) advocates a theory-driven approach to teaching English. More specifically, a theory of language learning should be the driving force behind the philosophy, goals, and practices of a good ESL program. He uses a case study of an exemplary ESL program in Central America in order to advocate a total overhaul of the U.S. English as a second language system. Nolan argues that ESL programs in the U.S. are less efficient and of lower quality than those he has seen in Central America. This is largely because ESL programs in the U.S. are most often sponsored by federal, state, church, or volunteer funding for a targeted clientele. Since the programs are not competing for students, Nolan argues there is less need or desire for a cohesive, unified program. 


\section{Holistic Approaches}

The varying needs and characteristics of second language learners from other countries demonstrates that many approaches to teaching English are too narrow in focus. Some research suggests that ESL programs need to use a more holistic approach when teaching English to immigrants and refugees. In addition to the linguistic needs of students, ESL programs also need to address students' cultural, affective, and motivational needs. Support services should be provided for students, so they can apply their knowledge to real life situations. "Adult ESL classes, while important, are only one part of an effective ESL program, which may also involve employment training, child care, and transportation" (Buttaro and King 2001:54). With a holistic approach, if ESL programs are to adequately serve their diverse populations, they must also provide other services that complement the language training. As we shall see, at least some of the programs examined in the present study also ascribe to a more holistic approach to teaching English.

Some research from cross-cultural studies helps demonstrate the importance of a holistic approach to second language learning. Berry and Williams (2004) found that Hong Kong students in the United Kingdom experience many problems beyond just language acquisition. The students experience sociocultural and affective problems along with language problems, and these three areas are often interrelated and overlapping. Upon arrival, immigrants may be unfamiliar with the culture of both the host society and the ESL program. At the same time, students' nervous and anxious feelings are often a direct result of being in an unfamiliar environment. These cultural and affective problems can negatively impact their language development as they struggle to survive in 
a new environment (Berry and Williams 2004). A holistic approach to ESL addresses students' affective and cultural problems, as well as teaching them English.

Similar affective and cultural challenges were reported in Sweden, where it was difficult for some immigrants and refugees to learn Swedish because they became isolated from the native population and unmotivated to learn (Elmeroth 2003). For refugees in particular, their social needs are hard to meet because they have become isolated and lack much direct contact with Swedes. A lack of integration into society leads to their marginalization. This same problem of isolation from the native population is also evident in the U.S., as immigrants frequently live near others that are similar to them. Some immigrants also work with others from their native country, so little English is necessary in their day-to-day life.

Lastly, a holistic approach to ESL teaching also considers the motivation of students to learn English. "Some researchers operate on the assumption that we acquire language when we need to use it...That need is not enough. No language learning can take place without contact with the new language and a comprehensible input" (Elmeroth 2003:432-3). If students lack motivation, they will not automatically absorb the English language as a sponge absorbs water (Harper and de Jong 2004). Rather, students need constant interactive contact with native speakers of their new language, which helps increase their motivation to learn. The constant interaction with native speakers also allows them to practice their English in a real-life context.

Contact with a population that speaks the target language is important for student motivation (Elmeroth 2003). In a study of the motivation of Japanese students learning English in Japan, Mori (2004) found that students have very limited contact with English 
language communities, since they are Japanese students learning English in Japan. He found that students were more likely to read in English if they had good study habits, and found an intrinsic value in stories and reading. To some degree, good study habits and a desire to learn are important when learning English as a second language. A holistic ESL approach must examine why students wish to learn English, because their motivation may affect how the ESL program is developed and refined.

\section{Limitations: A Lack of National Guidelines and Funding}

A reading of the literature suggests that national guidelines and funding, or the lack thereof, directly affect both the development of the ESL curricula and the ability of ESL teachers to prepare for class. In the U.S., adult immigrants do not have access to unified ESL programs that are supported by the federal government (Burns 2003; Nolan 2001). Many programs have minimal guidelines or influence from a national or federal source. Programs often operate as independent sites that offer some ESL classes and other services. In the U.S., adult ESL programs are often sponsored by federal, state, church, or volunteer funding. As a result, many of the programs are often challenged to constantly find more funding, as well as enough staff and teachers to address the growing demand for English classes from an expanding immigrant and refugee population.

Unlike the U.S., some other countries do have a cohesive, federally funded ESL program. Australia, for example, has had a stable, federally funded ESL settlement program for new adult immigrants for over fifty years (Burns 2003). This program resulted from a push for "common national learner pathways involving explicit curriculum statements and the profiling of learner assessments in eight areas of learning" 
(2003:270). Australia's ESL program has ensured a level of continuity and stability in their delivery of ESL services.

ESL programs in the U.S. are not organized on a rational level, and this is reflected in the program curricula. They rarely utilize clearly defined theories of language learning as the basis for their classes. For example, the theory used in Nolan's (2001) case study was called "Languistics." According to this theory, "every language has a particular structure. Until the learner internalizes that structure, communication remains defective... The learner must first master the basic structure of the language before engaging in free, unguided conversation" (Nolan 2001:8). One of the benefits of a theory-based program is that a language theory provides a common direction for all classes to follow, as well as some continuity that provides a sense of purpose and direction for both the students and teachers. By contrast, ESL programs in the U.S. often follow curricula and teaching methodologies provided by commercial sellers, where the theory is embedded in the materials. Therefore, the program alters every time they acquire a new set of materials (Nolan 2001). Paradoxically, this situation also produces programs that closely resemble each other, since programs do not emphasize a language theory to distinguish themselves from other programs.

The presence or absence of national ESL guidelines and funding also directly affects how teachers approach their classes, in terms of both quality and preparedness. More funding in the U.S. would allow ESL programs to hire and support more highly qualified teachers. In Nolan's (2001) case study, the adherence over several years to a specific theory allowed for a pre-service teacher training program and the continuous fine-tuning of the teaching methodology. Teachers in this program were required to be 
college graduates, pass a test of native quality English, and demonstrate commitment to teaching ESL. Most also had elementary or secondary teaching certificates. However, in the U.S., many programs use teachers who must come up with their own materials and lesson plans for each class. Many adult ESL teachers lack sufficient preparation to be effective, and are mostly unprepared, marginalized, and isolated (Orem 2001). Those teachers who do have a significant amount of experience and training are in the minority, and most teachers work as part time teachers and volunteers (Crandall 1993). Many ESL programs have a very high turnover rate of teachers. This places a heavy burden on programs to provide meaningful staff development. 


\section{CHAPTER IV}

\section{METHODOLOGY}

This study seeks to understand the structure and processes of several different ESL programs in one city. The purpose of this study is to determine the structure of the organizations that offer ESL classes, and evaluate how they approach teaching English to immigrants and refugees. The study uses in-depth, semi-structured interviews with both program coordinators and ESL teachers at several different ESL programs (McCracken 1988; Rubin and Rubin 1995). In addition to the interviews, the methods also include a small document analysis of items such as organization websites and pamphlets about services that they offer.

Since ESL programs in the U.S. are so different and lack a unifying structure or set of guidelines, the present research focuses on several aspects of organizations in one county that offer ESL classes. As a qualitative, comparative study, one of the goals is to gather as much data about each organization as possible. This type of study helps describe the structure and processes of each organization. Specifically, this study examines the content of classes, teaching styles, and the teaching philosophy of several different organizations, as well as the structure of the organization and connections to other organizations. This comparison allows an assessment of the goals and philosophies of many separate, distinct ESL programs. This type of qualitative, comparative analysis helps examine to what degree these organizations are disjointed and independent, as well 
as offering some insight into the advantages and disadvantages of having such a segmented ESL system.

Qualitative interviews provide a very rich data set for this project. Qualitative interviews provide much better descriptions of the structure of these organizations than written survey instruments. A quantitative analysis may have just given insight into how many students these programs serve, how big the budget is, and what other programs they offer. Qualitative interviews offer a better understanding of why organizations have certain policies in place, why they teach English a certain way, and how they deal with complex problems and challenges. Qualitative interviews allow a very detailed description of the structure and rationale behind the organizations.

The qualitative interviews essentially serve as in-depth conversations with the subjects. Although there was a detailed list of interview questions for both the coordinators and teachers (see Appendices A and B), it was not followed exactly. Instead, the interview questions guided the general direction of the conversation to make sure all the necessary topics were covered (Babbie 2004). For example, respondents often answered questions on the list well in advance of their order on the list. The interviews were conducted such that respondents did most of the talking. They were guided through the conversation, and probed for clarification on some of their responses.

A convenience sample of potential organizations was initially gathered from an Internet search of ESL programs in the area. By talking with some of the program directors, a snowball approach was used to expand the list of potential ESL organizations. Eight total interviews were conducted at six different locations. The names of the organizations have been changed to maintain confidentiality. Four of the interview 
locations were at non-profit organizations. They are coded as the Northern, Southern, Eastern, and Western organizations. Subjects were also interviewed at a local community college and the adult education department at the public school system. Six of the interviews were with the ESL program directors at their respective ESL program. Each of the other two interviews was with a teacher at the Northern and Southern organizations. A teacher was not interviewed at every organization. In one case, at Eastern, the ESL program was extremely small, and the director was also a teacher. At the community college, the program director also taught several classes, so she was questioned as a teacher as well as a coordinator.

Prior to conducting the interviews, approval was granted from the Human Subjects Protection Program Office at the University of Louisville to ensure that the rights of the human subjects were protected. All of the interviews were tape recorded, and the tapes were transcribed as soon as possible after the interview. The transcribed interviews were eighty-one pages long. When reading through the interviews, themes, key words, and interesting concepts were marked on the transcriptions. A separate file was created to keep track of the page numbers and interviews in which certain themes were mentioned, so they could easily be referenced in the future. The interviews lasted from forty-five minutes to a little over an hour. All interviews were conducted at the organization where the subject worked. The ESL coordinators were interviewed in their office. The two teachers were interviewed in an open office or an empty classroom. There were two instances where the tape stopped working or was cut off prematurely. These sections were filled in based on the interview notes right after the interview. 
The qualitative, semi-structured interviews allowed misunderstood questions to be clarified in order to obtain more relevant responses. Both the respondent and the organization environment could also be observed (Babbie 2004). Qualitative interview design should be flexible, iterative, and continuous, rather than prepared in advance and locked in stone (Rubin and Rubin 1995). Neutral questions were the goal of the interviews, so as to not influence a respondent's perception or answer to a question. The first few interviews revealed some questions that were confusing or unclear to the respondents, and these were changed or eliminated. In-depth interviews provided an agile instrument to capture the respondents' thoughts about their ESL programs. They allowed data to be captured that was "needed for penetrating qualitative analysis without participant observation, unobtrusive observation, or prolonged contact" (McCracken 1988:11). Rather than reliability and validity, Rubin and Rubin (1995) argue that transparency, consistency-coherence, and communicability are a better fit for qualitative research. Good interviews should be clear and understandable, and the researcher should demonstrate that core themes occur across the interviews.

The semi-structured interviews with ESL coordinators provide a clear understanding of how each organization operates, what their philosophies and goals are as an organization, and how the organization is structured as a whole. They offer a broad understanding of the structure of the organization. At the same time, interviewing some ESL teachers provides a glimpse into the structure and processes of some of the classes, as well as some of the materials and teaching strategies used in those classes. Semistructured interviews with teachers allow an in-depth description of the processes at work within ESL classrooms. 
Besides the interviews, observations of the organization during the interviews were noted, as well as information contained in documents such as pamphlets, job descriptions, and organization websites. This multifaceted approach provides a broader range of information on the ESL programs than if only one methodology had been used, although the interviews did provide the vast majority of the data. The small document analysis provides further information about the organizations that ideally reflects the information gathered from the ESL coordinator interviews. The observations both during the interview and while at the organization offer a brief glimpse into the appearance and physical layout of the organization.

I also personally have some experience as an assistant ESL teacher. I served as a volunteer ESL assistant teacher for a few months in 2004 , and I also volunteered at one of the organizations in the current study, Northern, where I designed some Internet-based lesson plans. During this volunteer work, I also had the opportunity to fill in for an absent ESL teacher, and I taught a $31 \frac{1}{2}$ hour class by myself on two occasions. Although observations from my experience as a volunteer are not included in the present study, they do serve as background experience that helps to inform my research.

Based on the literature, there were three expectations regarding the present study. 1.) Most of the ESL programs would be segregated and distinct sites that operate independently of each other. Likewise, there was an expectation that many of these organizations would be under-funded and -staffed, and they would therefore be somewhat ineffective at teaching English to the students. 2.) As shown in both the ESL and immigration literature, it was expected that the students would come from extremely diverse backgrounds, and this diversity would present many unique challenges to ESL 
programs. 3.) It was also expected that new assimilation patterns, featuring a greater acceptance of cultural differences, would lead to services that are strongly client-oriented. The programs would likely focus on teaching survival English and communication based on the needs of the students. Overall, these programs were expected to be very loosely organized and structured. Based on the literature, it seems that ESL programs as a whole should look like a patchwork quilt that has been sewn together, with little consistency among the different programs. 


\section{CHAPTER V}

\section{FINDINGS: ORGANIZATIONAL STRUCTURE AND CLASSROOM DYNAMICS}

For this study, six ESL program coordinators and two other ESL teachers across six different organizations that offered ESL classes were interviewed. Four of the organizations are non-profit organizations, one is a community college, and the other is the Adult ESL Education department at the public school system. The non-profit organizations are all relatively small compared to the community college and public school system, in terms of both the amount of ESL classes they offer and the number of students they serve. The non-profits are primarily funded by state and federal grants, as well as a variety of donations. The community college is the only organization funded partly by student tuition, in addition to state revenues. The Adult Education ESL program at the public school system is funded primarily by grants. The number of students attending class at any one time ranges from about twelve to fifteen students at one of the non-profit agencies, to several hundred students at the community college and public school system. Most of these programs have textbooks and guidelines available, but the teachers also supplement the ESL classes with their own materials and resources. As a result, no two classes are ever exactly the same.

\section{Structure of the Organizations}

Each organization is structured differently and approaches teaching ESL in slightly different ways (see Appendix C). Eastern is a fairly small community center that 
serves a neighborhood that is $85 \%$ immigrant and refugee. The only employee that works directly with the ESL program is an Americorps VISTA volunteer. About three other volunteers help with the ESL classes. Eastern is funded primarily through the Metro Government, who they also report to on how they are spending the funding. They offer two ESL classes, one in the morning and one in the evening. They also provide other services to the community, such as a food pantry and youth services.

Similarly, Western is fairly small, although it has grown over the past fifteen years. Western only employs four full time staff members, so they rely extensively on volunteers and partnerships with other organizations. Their services are divided into three key areas: youth programming, adult education, and community building. However, their ESL program is run completely by the public school system. The public school system offers ESL classes in Western's building. They use two teachers at Western to teach a morning class and an evening class, as well as a clerk that does all the testing and registration.

The other two non-profit organizations are Northern and Southern. They are structured a little differently from Eastern and Western. Northern works exclusively with refugees, and is contracted through the State Department as a resettlement agency. Their main goal is to employ the refugees, which must be accomplished within ninety days. With an ESL budget of around \$200,000, Northern employs an ESL program manager and three teachers, and also brings in a fourth teacher from the public school system. Several volunteers help with the program. Most of their funding is through state and federal grants. Northern is considered a stand-alone agency because they do not have another organization that directly oversees them and gives them direction. Northern 
offers four ESL classes; a beginner class, two intermediate classes, and a more advanced class. They usually have about fifty students attending class at once, which is a mandatory part of the resettlement process. The classes meet every morning during the week, and there is also a cultural orientation class on Wednesdays. Since they work with refugees, the classes are porous and constantly changing. The number and type of refugees they serve come in waves, depending on who is allowed to come to the U.S.

Southern is a uniquely structured organization located at a horse racetrack. The director is the only full time staff person, although two Americorps VISTA volunteers also work there full time. They plan to hire another full time employee sometime in 2006. They serve the large number of Spanish-speaking racetrack workers, and this is the only program of its kind in the country. They also run a smaller program at another location. At the main program, class meets Monday and Tuesday evenings, which is the only time the workers can regularly attend. They employ three part time teachers that teach a beginning, intermediate, and advanced ESL class. They also provide reading partners, tutors, and conversation tables for students to come in and practice with native English speakers. Last year, 104 students were enrolled in classes, although much fewer than that attended class on any given night. They also have about thirty or forty regular volunteers. Southern is fiscally independent, with a budget of about $\$ 150,000$ per year. Much of their funding comes from grants and donations, although they have a wide variety of funding sources.

The community college is structured differently from the non-profit organizations. The ESL program there is one of many distinct programs within the college as a whole, and is situated within the Humanities division. Their funding comes from state revenues 
and student tuition. The ESL program is a developmental department. Teachers prepare students to be able to take other courses in the regular curriculum at the college. They employ three full time ESL professors, and also use ten or twelve part time or adjunct instructors. They provide grammar, reading, conversation, vocabulary, and listening courses. They have a basic level, two intermediate levels, and an advanced level. The classes are offered at different times throughout the week to accommodate the schedules of the students. Between four and five hundred students are enrolled each semester.

The ESL program of Adult Education at the public school system is the biggest ESL program in the present study. Around twenty-five people are employed by the program, only three of whom are full time employees. In the last fiscal year they had about ten volunteers working with different ESL classes. While the paid ESL instructors provide all of the class materials, the volunteers help the instructors facilitate the classes. The public school system provides ESL classes at eleven sites throughout the county. These sites include faith-based organizations, community centers, and schools. They are offered at a variety of times and days throughout the week. Several of the sites have enough students for three or four classes, while some sites only have enough students for a single class. They have six levels of their basic ESL classes; beginning literacy, beginning, low intermediate, high intermediate, low advanced, and high advanced. They also offer GED classes, family education classes, and work force classes.

\section{Goals of the ESL Programs}

The goal of most of these ESL programs fell into two categories: to help students communicate in English, and to help them accomplish daily challenges, such as getting a job. Northern, Eastern, and Southern all mentioned communication as an important goal 
of their ESL programs. Since $85 \%$ of the families around the Eastern neighborhood are immigrant and refugee families, their primary goal is to increase written and verbal communication. The teacher at Northern stated that for the students to be able to function in the society at large, they must be able to communicate with, speak, and understand American English. Likewise, one of the main goals at Southern was also for the students to be able to communicate well in English. The director of Southern stated that part of their purpose is to help meet the communication needs of the students. The community college also supports communication as an important skill. They cooperate with other classes so the students can boost their speaking confidence.

In two cases, the goal of communication is also intimately connected with being able to function on the job. As a supplement to classes, Southern offers conversation tables once a week, where "students can come in and practice just speaking, which is really their main push, because in their job, that's what they need most, is to be able to speak." The director at Southern also said that communication and vocational knowledge really go hand in hand. "You can't advance in your job without learning English and being able to speak to your boss, but you also can't learn your horseman job without being able to be trained in English." Furthermore, she acknowledged that there is a communication gap between the Spanish-speaking workers and the English-speaking bosses. Their classes are meant to bridge that gap for the workers, so they have the language skills they need to communicate with their boss. Communication and employment are also linked at Northern. Their refugee students begin working within a couple months of starting ESL classes. As a result, they try to emphasize talking and 
listening in the classroom more than reading and writing. Talking and listening skills help them function in English on the job easier than the other skills.

The second major goal mentioned by most of the organizations relates to bettering the daily lives of the students. Usually, this means getting hired or advancing in a job. All four non-profit organizations mentioned this goal. Northern and Southern focus the strongest on English as a way for immigrants and refugees to have a better chance of being hired and to advance in their current job. The director at Northern stated that "the ESL program is geared towards getting clients familiar with the language and cultural aspects of living in the United States in preparation for work." The end goal of Northern's classes, as well as the rest of the services they offer, is for their clients to be employed. More specifically, Northern is required to have refugees employed within ninety days through a contract with the state department. Northern also uses materials in class that relate to employment, such as job applications and practice interviews. They occasionally take students to job fairs so they can get a feel of what working in the U.S. might be like. Northern's overall mission is to resettle refugees and help them find employment. As a result, their ESL classes focus on teaching English skills that will be useful at work.

One of Southern's primary goals is providing ESL classes that help the racetrack workers advance in their jobs. According to the director, Southern is trying to meet a workforce need by teaching "thoroughbred terminology, things related to the horse, things related to the actual track depending on the type of job someone does,...so it's kind of English for specific purposes." One of their main purposes is to teach English terminology that is directly applicable to a student's specific job. English skills are 
directly related to an immigrant's chance for upward job mobility. Most immigrants at the racetrack start as a hot walker, which is just a person who walks a horse in a circle. This job requires very little English skills, as they only need about five phrases to walk a horse. To be a groom, which is the next highest job, they have to understand what their boss tells them to do, as well as give feedback to their boss in English. Learning English helps immensely because according to the director at Southern, "as their English language skills improve, they get more opportunity for more responsibility and more pay in their jobs." Learning English is often essential for immigrants who want to find a job or advance in their current job.

The public school system has different goals depending on what kind of class is being taught. The family education classes try to teach parenting skills and the American school system, while workforce classes teach vocabulary specific to a particular workforce environment. The goal of the general ESL class is more universal, providing classes that are aimed at teaching life skills, and focusing on the specific and individual needs of the students. They also have some goals that are a result of their state grants from Kentucky. They are held accountable for enrollment numbers and student performance. For example, the director said that "basically $50 \%$ of our students at each level have to test into the next level" this year. Their goals vary because they offer so many different classes to a large number of students.

The community college primarily focuses on academically-oriented goals, in addition to the goals of communication and employment. According to the head of the ESL department, their academic goals are three-fold. The coordinator at the community college said that they try to prepare students for long-term educational goals, "perhaps to 
transfer to a four year institution, perhaps to complete an occupational certification of some kind, or perhaps to enhance lifelong learning." 'These goals are consistent with the overall mission of the college. The community college, as a whole, prepares students to gain employment certifications or to move further along in their education. The ESL program is a developmental department. Their leveled courses are meant to help students be able to take courses in the regular curriculum or gain a technical certification. The program mostly serves students who do not earn high enough scores on an English as a Second Language test. From this program, they will have enough English to make it through a regular class. Most of the ESL students go on to take courses in the regular curriculum at the community college, while a smaller number of students take the ESL classes for personal improvement.

\section{The Philosophy Behind the ESL Programs}

The organizations in this study have very different philosophies and rationales for offering ESL classes. Both Southern and Western have similar philosophies behind their respective ESL programs. Both of these programs try to fill a need in their community as the immigrant population changes and grows. Southern was created at the racetrack in 2004 because of a "demographic shift in the backside of thoroughbred horse racetracks." The shift was from mostly African American workers to a majority Hispanic population. At the time of the interviews, the backside workers are composed of about $60-70 \%$ Spanish-speakers. This demographic shift has also occurred at racetracks around the country. As a result of this huge influx of Hispanic immigrants, Southern was created to help them with their communication and job-related English needs. Southern "wants to be a model program for the thoroughbred industry, because there's not a standard 
program like it throughout the country." They are trying to meet the language and educational needs of a community that has been largely overlooked.

Western was also created to fill a need in its community. The need arose for convenient English classes in the community as large numbers of refugees and immigrants settled in the area. This community center was formed fifteen years ago, as the first refugees were being resettled in the city. As this resettlement happened, "some neighborhood issues came up, and then some unique needs that the community hadn't seen much before, like the need for English classes. And clearly as more children were coming into the community, the need for a community center." Western was created in response to a neighborhood and community that was drastically changing.

Eastern also tries to address the needs of a large immigrant and refugee community. They are an on-site resource that residents can use to find information, get help with social services, and attend ESL classes. Here, the ESL classes are entirely voluntary. The rationale behind them is that immigrants and refugees "need someone who can lay out the rules for you and give you examples in order to be on your way to mastering even the basics... If their English language level was higher, some of these problems would go away for them." Ideally, the program at Eastern will help students improve their English skills. As a result, they may be more capable of solving some typical problems on their own.

Due to its organizational structure, Northern has a slightly different rationale for offering ESL classes to its clients. Northern's mission is to resettle refugees and offer services to make their adjustment a little easier. As a refugee resettlement program, they are "contracted by the State Department to provide services for refugees, and the driving 
force behind that contract is resettlement." One of the most important services they provide is to help the refugees find jobs. Since this service is so important, the ESL program is meant to familiarize their clients with the English language and culture in the U.S., so they have an easier time when they find a job. As part of the resettlement process, the refugees are required to attend English classes. The ESL program at Northern is just one of many services that are available to refugees to help them adjust to U.S. culture and successfully earn a living.

The director at the public school system stated that, "Basically, we' re trying to get people who have moved into the United States to become participating members of the community. And offering ESL classes or GED classes, skills-enhancement classes, helps them become more actively participating citizens. Not 'citizens,' citizens, but citizens of the community." The primary purpose behind their ESL program is to help immigrants and refugees become active members of their communities, and teach them the English they need to function in their new environment.

Lastly, as mentioned above, the community college is quite different from the non-profit organizations. It is a developmental program that is meant to help immigrants transfer more easily into the regular classes. The ESL classes do not count towards a degree at the community college. Instead, their purpose is to improve the English ability of their students, so they are prepared to take other classes at the college with native speakers of English. Here, the focus is less on providing English necessary for a job or everyday tasks. Rather, they focus more on education and life long learning. 


\section{Funding}

Five of the organizations are funded by a variety of grants, donations, and state and federal money. Significantly, they also report consistently being under funded and needing to constantly seek out new sources of funding. Although it is by no means an abundantly wealthy organization, the community college is funded through a combination of state revenues and tuition. The community college did not specifically cite funding as a problem for their program, although that question was not specifically asked to any organization. Any financial concerns arose in the course of the interviews.

The non-profit organizations reported that they are primarily funded through a combination of state and federal grants, financial and in-kind donations, fundraisers, and mailings. The size of the budgets for these ESL programs ranges from less than $\$ 1,000$ to around $\$ 200,000$. Northern and Southern reported bigger yearly budgets, in the range of $\$ 150,000-\$ 200,000$. Eastern reported that their yearly budget is maybe $\$ 1,000$ or less, and mostly went towards the cost of books and some other small expenses. Western reported that their entire organizational budget is fairly small and limited. Since the public school system completely runs their ESL program, Western's ESL budget is effectively zero. However, they do provide the physical space used to teach the classes.

At Northern and Southern, the budget is divided up between staff salaries, classroom supplies, and several other budget items. Northern also uses its budget to provide a bus pass to eligible students, which allows them to get around town and to get to and from their ESL class. With a slightly larger budget, Northern pays a few more staff members in the ESL program. They pay the director and three ESL teachers, all of whom only work there part time. Southern's budget includes the director's salary, 
educational materials, matching funds for two Americorps workers, and it also includes some money to hire another full-time staff person sometime this year. In contrast, Eastern's budget is around $\$ 1000$, and the only employee is an Americorps worker. Western does not have anyone who works directly with the ESL program, since it is basically contracted out to the public school system to run.

All of the organizations interviewed reported feeling financial pressures to some degree. For example, the director at Northern stated that:

"We're really under funded, understaffed; it's a really challenging job. We're always looking for new funds, to provide more of a comprehensive approach. There are so many different things we could offer, computer classes or, I think (Northern) does a really good job providing a lot of different services, and making it a comprehensive approach. Other agencies aren't really able to do that. It's a concern for all agencies, for funding, for staffing."

In this case, a tight budget and a lack of funding and staff meant that they are not able to offer all the programs and services that they wish they could. I volunteered at Northern for a sociology class. They asked me to spend my time creating ESL lessons that utilized computers and the Internet. They had a computer lab with five fairly new computers, but teachers rarely used it because nobody had time to work with it. A bigger budget or more comprehensive funding may allow some ESL programs to offer a greater variety and quality of services to benefit the students.

The Adult Education ESL program at the public school system is primarily funded by grants and in-kind donations. Their budget for the entire adult education program is about two million dollars per year, although she did not report how much of that goes towards the ESL program. Much of their budget comes from grants from the state of Kentucky, which has grant funding available to all adult education programming in the state. They also expand their services by looking for other organizations that need 
an education provider. They "look for organizations, like faith-based organizations, who want to provide educational classes, and they would come to us and we would write a grant together." So they also write grants with other service agencies, and then work together to provide different ESL services. For example, someone from a Buddhist monastery recently approached them to write a grant together. The public school system also uses donated physical locations as classroom sites. Western lets them come to their building to teach ESL classes, as do several different churches and the general public school system.

More funding and a bigger staff could greatly benefit all of the programs in this study. Even the community college, which is funded through state revenues and student tuition, reported feeling the problems associated with a tightening budget. Although the ESL department head could not tell me how big the budget was, she did report on the tightening of state funding and how colleges everywhere have had to raise tuition. This puts pressure on all parts of the system, including the ESL program. Due to limitations on funding, staff, and resources, many of these programs routinely improvise to meet the needs of a given situation.

\section{Curriculum}

The most common theme mentioned when the directors and teachers talked about the ESL curriculum is that all teachers use their own materials to some degree. In other words, all the ESI $\_$teachers create their own lesson plans as they see fit. However, some of the programs do loosely follow a core set of books or materials. For example, Eastern has accumulated a master set of textbooks over the years that teachers and volunteers make copies out of for the classes. These books are a combination of what the public 
school system uses, and some others that they have purchased on their own. This wide variety of on-site books and materials allows teachers to pick and choose what is needed for class on any given day. The coordinator/teacher at Eastern said that "What I have and I use is just kind of a random selection I can pick and choose from." However, they do have a book they use regularly with the Hispanic students. It is in English and Spanish and "gives a more comprehensive view of English." Northern is similar to Eastern in that teachers are able to mix and match materials for lesson plans. Since many of their teachers are retired, they pull a lot of materials from their own personal resources. However, all the teachers do follow a set of guidelines passed down from the Office of Refugee Resettlement.

Southern is going through a transitional period. Last year, their curriculum was similar to Eastern's and Northern's, in that each teacher developed their own curriculum. This year, they adopted a text called STAR, which they plan on following. According to a teacher at Southern:

"It's not going to be a complete curriculum, but having this as a guideline, we will know what the teacher previous has covered, and what will be needed to go on to the next class. And that will bring a little continuity, rather than each of us doing our own thing, there will be a guide. But there will still be a need for the other resources that we bring into it. The textbook can't do it all."

So even though the three teachers there will follow the same set of materials, they will still bring in other resources to individualize the program.

The public school system has several different curricula that instructors can utilize, such as Focus on Grammar and a series called All Star. The units and topics picked out of those books are not mandated or consistent throughout the program. Teachers choose what they need to use from a resource library at the main office, as well 
as classroom sets at the various sites. Teachers freely bring in their own curriculum and books, as well as other materials and resources that they have found on their own. Some of their teachers also utilize Internet resources and websites about teaching ESL. They do have a couple of rigid curriculums that they occasionally use, such as a civics and government curriculum, in addition to a few classes that are more academically-focused.

The community college uses a common set of textbooks in each class, which the teachers then supplement with their own materials on an as-needed basis. The department head stated that "in virtually any course, I think all the instructors will supplement appropriate materials that they find or that they invent, around that common material." At the community college, all the teachers work together to pick out the textbooks that will be used in each of about fifteen classes. They look for the best textbooks available for their purposes, and hang onto them if they work well. They also have a few courses without textbooks, and the instructor puts together the curriculum for that individual class.

\section{Teaching Strategies}

Most of the teachers use similar strategies in the classroom. One of the most common strategies is to try to get the students involved, so they can communicate and talk to each other. A teacher at Northern tries to keep the class "as interactive as possible, have it kind of student-based in so far as possible. Not having the teacher just drone on at length. Because really it's all about the students being able to function, to produce language. So I'm asking a lot of questions. Also, I put an emphasis on having the students listen to the other students in the class." This strategy makes a lot of sense, given that Northern is trying to teach the students how to communicate and be able to 
function on the job. Besides this focus on communication and interaction, teachers also use a lot of other standard teaching strategies. They use things such as worksheets, audio and video tapes, short presentations, and pair or group work.

One teaching strategy that was regularly addressed involved using realia. Realia is a term for real world, physical objects that are used in class. A teacher at Southern talked the most about realia. "I use as much realia as I can. When we talk about shopping, I bring in store ads. Banking, I have samples of checks, registers... I keep adding more realia, you know, real things, and I move along as I'm collecting. So I try to incorporate as much of that as I can." Realia can be especially beneficial when teachers are teaching real world concepts or skills, such as going to the bank or applying for a job. At Northern, they constantly drill students on information that is on a job application, and practice filling them out. They also practice reading bus schedules, writing checks, and reading the dosage instructions on medication. Realia is also useful in beginning classes. Students that "are not literate in their own language, we use a lot of physical objects and gestures with that group." This strategy can be a great help for students who are completely illiterate.

\section{Survival English}

A teaching strategy commonly mentioned by the teachers and coordinators is survival English. The term survival English is used interchangeably with life skills in both the literature and the interviews. Survival English refers to teaching students common skills that are useful to them in their daily life, such as going to the grocery or the bank. Two of the organizations in the present study, Northern and Southern, heavily focus on teaching life skills to the students in English. At these two organizations, both 
the director and the teacher commented specifically on teaching English based on life skills. The coordinator at Eastern also indirectly discussed teaching life skills.

The goal at Northern is to get the refugees employed as soon as possible.

Therefore, it is important to teach them a functional, life skill-based level of English that will help them both on the job and in their everyday life. The teacher at Northern described the curriculum he bases his lessons on:

"That curriculum for refugees is a kind of survival English, kind of a functional, skills-based curriculum. They're supposed to know how to have the communication skills to get along, in our society, for example, to count money, to make a doctor's appointment, to ask for directions. To go into the doctor, announce themselves, describing their ailments or illnesses, a lot of job-related English."

This skills-based curriculum is the basis of the program at Northern, what the teacher referred to as the "meat and potatoes" of the curriculum. This type of teaching ties in really well with their overall mission.

While there is some variation in how the four teachers at Northern teach, they all focus to some degree on teaching practical life skills. The unifying characteristic of the classes is a picture dictionary and a regular dictionary that are provided to each student. According to the director, the teachers use the picture dictionary "really heavily, because it's life-skills based, so there's the section about the house, about shopping, about work. And it not only provides the basic vocabulary but it provides questions that you might ask students to engage them in using this vocabulary." The use of this picture dictionary is consistent, to some degree, among all the teachers. Northern also constantly drills students on personal information, which are things they may be asked in a job interview. In classes, students are constantly asked about their name, their address, where they're from, and what their skills are. Other life-skills topics that are commonly discussed in 
the classes are hygiene, medical issues, appointments, apartments, and furniture.

Hygiene, in particular, is a pertinent topic because there are often cultural differences about hygiene. Despite the focus on life skills at Northern, "each teacher addresses it differently. Some focus more on grammar than vocabulary. You're trying to build vocabulary and associate that more with life skills. Then you're also incorporating grammar as well."

Employees at Southern also talked a great deal about the importance of teaching life skills to the students. The teachers at Southern all use the same textbook as a guide to provide some level of continuity to the classes. Teachers are still free to use their own resources and create their lessons based on their needs. The teacher said that "in my class, I try to incorporate, of course, life skills, which they are very much interested in. Clothing, shopping, banking, things like that. I included grammar, vocabulary, spelling, writing, structured writing, dialogue... Whatever they would need to function in our society, I try to include." Using these everyday tasks as the focus of the English classes helps the students function in society, and also helps them converse in English with native speakers. This curriculum based on survival English may be especially useful for the students at Southern because what they need most is to be able to communicate with their boss. As racetrack employees, students do not have to be able to read and write, or have a GED or a high school diploma. They do need to be able to understand and communicate with their boss, which makes survival English more pertinent to their everyday life. Furthermore, unlike refugees, the workers at the racetrack "are here making money to send back home, and plan on going back to Mexico." 
The director at Southern expanded a little bit on how course materials focus on life skills. She said that "we try to give our students a broad range of skills so that they can be successful in our community as well." Their life skills program is based on the CASAS competencies, which stands for Comprehensive Adult Student Assessment System. The competencies are composed of nine broad categories, including "communication, economics, community resources, health, employment, governments and law, computation, learning to learn, and independent living." The materials they use in the classroom correlate with the competencies, so they teach around this particular skill set. Depending on what curriculum is used, they can determine what skills are being taught as they look at the lesson.

Eastern also occasionally referred to teaching life skills, albeit indirectly, as did the public school system. Although the director/teacher at Eastern did not specifically mention incorporating survival English into the classroom, she did comment on changing the curriculum based on the students in the classroom. "We' re really planning the lesson right as class is starting, to sort of cover material that's applicable to the students that are there that day." "The curriculum is different for each class, depending on the teacher and the students in class that day. So the lessons are really catered to what the students need on any given day. The general ESL classes are based on teaching life skills. They also use CASAS as their testing system, which tests students on over 300 competencies based on different life skills. 


\section{CHAPTER VI}

\section{FINDINGS: THE PROCESS OF TEACHING ESL}

Over the course of the eight interviews, several other themes also emerged about the processes of the ESL programs. Two of the themes show that many of these programs utilize a wide variety of available resources in their programs, and they also rely on improvisation to compensate for unique situations that arise. These programs' use of multiple resources and improvisation is often a result of small funding and a relatively small organization size overall. Many organizations mentioned using a holistic approach, in which they try to teach more than just English skills to their students. All of the organizations also reported on the diversity of their students, and how this affects their ESL program. Lastly, every organization stated several difficulties and challenges that arose when teaching ESL. The interviewees voiced these concerns even though they were never specifically asked what was challenging about teaching English to immigrants and refugees.

\section{Interconnections: Drawing on All Available Resources}

Since most of these organizations operate with relatively small budgets, they rely heavily on the ccoperation of other groups and organizations to supplement their ESL program. All of the organizations in the present study either partner with other organizations or groups, or cooperate to some degree with other groups to supplement their own programs and services. Of all the interconnections among the ESL programs, 
the most common collaboration involves the program at the public school system. All five ESL prograrns reported cooperating with the school system to some degree.

Northern has four teachers, three of whom are employed part time specifically by Northern. The fourth teacher, however, was hired through a partnership with the public school system, so she is paid partly through the school system and partly through Northern. Southern works with the school system on their English assessment tests. For them, the school system provides "an in-kind donation of the costs of the assessment materials, and a staff person that comes in". The public school system tests all of the students at Southern, and provides them with the results so students can be placed into an appropriate class. Eastern uses some of the same materials and books that the school system uses. The school system sometimes sends a teacher there, and provides literacy classes for some students. The coordinator at Eastern also reported that they "tried to get (the school system) to do more here, but the staff hasn't really wanted it, because we really like the freedom here to cater to the needs of students."

Western relies on the public school system the most, since the school system is completely in charge of the ESL program at that location. The coordinator at Western stated that they provide the "space and support, and they (the school system) provide the program, the teachers, the materials, and their curriculum and all of that. So they have pretty much taken over the third floor of the center with a combination of ESL classes, GED classes, and a few other adult education programming." The public school system runs the entire program at Western, including hiring the teachers and coordinating the classes. The community college also partners with the public school system. They work together on things like "easing students" transition into the community college... An 
example of what they do is, they offer some free, non-credit courses on our premises for students who are not quite ready to join the regular courses. They can come in, they can kind of get their feet wet, they can get some preparation for entry into what we offer."

All the organizations in the present study also cooperate with a wide variety of other agencies, groups, and programs to supplement their own services for the immigrant and refugee population. Four of the organizations, Northern, Southern, the public school system, and Western, partner with various libraries in the city. An outreach person from the library may come regularly and connect students with library materials, or come to the classes and sign students up for library cards. Southern also works with the public library to show some of their students' artwork at a local branch. Other examples of partnerships with the ESL programs include the metro government, cooperative food pantries, local high schools and colleges, book donations from libraries and Barnes and Noble, the DMV, free tax preparation, and legal help from the local Bar Association. Some of these partnerships are used within the ESL classroom, such as extra volunteers and books that have been donated. However, many of these partnerships are supplementary services that can be accessed by the students in addition to their ESL classes. For example, after an ESL class, students might be able to get help with their income taxes, or go to information sessions provided by other organizations.

\section{Improvisation: Working With What You Have}

One theme that arose from the interviews at the non-profit organizations is that the programs are improvised to some degree. Regularly, teachers adapt lesson plans and materials to fit a changing student population, piece together a curriculum based on a widely varying set of materials, and work in a challenging teaching environment. This is 
largely the result of having a small budget and staff. Although the ESL program at the public school system is larger than the non-profit organizations, their teachers are also free to piece together their classes based on what they think is needed. In contrast, the community college seems much more structured and rigid in its format, utilizing more traditional classroom spaces and having more continuity in the course materials.

As a refugee resettlement agency under contract with the State Department, Northern has little choice in how many refugees they have as clients at any one time. Sometimes ESL classes will be relatively small if the influx of refugees is low. But certain times of the year routinely bring a larger number of clients to Northern. The director reported that they probably average around 50 students in four different classes at any one time throughout the year. However, September is typically the busiest month for arrivals. In the winter of 2005-6, they had around 70 students, which "put a fair amount of stress on the program because of the size of classrooms. So I was really working, trying to find volunteers that could sort of supplement the classes, either work in the classroom with a teacher and assist, or we could break off into small group conversations." The classrooms Northern uses are not big enough to accommodate 70 total students. So they had to improvise, and either find ways of cramming more students in a small space, or utilize more volunteers to break the classes into smaller groups.

In order to provide ESL classes to clients, Northern has to utilize the resources that it has available. This includes making the best use out of a limited amount of space by converting older rooms into classrooms. A teacher at Northern described the layout of his converted classroom:

"The building here was formerly a nursing home. So I'm in a smallish room... In the room is a very small board, a portable whiteboard, in the corner of the room. I 
guess there's a sink in the room and a closet, I think it was somebody's apartment, a very small apartment... We have a problem because some students have to have their back to me, we have to try to fit all the students in that small space."

Having been in this classroom myself, it is very small and somewhat difficult to teach in since it was not originally designed to be a classroom.

Southern and Eastern both had similar problems with utilizing classroom space. Southern is lucky enough to have been well funded when it was founded two years ago. So they have a very new, fresh, modern building complete with a very up-to-date computer lab. They have three different classes, but only one meets in a 'traditional' classroom. Another class meets around tables in the library/reception area, and the last class actually meets in the computer room. The class that meets in the computer room poses the biggest challenge. The teacher of this class reported that "because it is a computer room, and the computers are set up, I am not free to move furniture around. Just tables set in rows for the students." Since the computers are set up, the students have a smaller space in which to set up their materials and notebooks. Eastern also uses a fairly small classroom for its classes, although the classes themselves are not very large. "We have two long tables pushed together that everyone sits around. It is somewhat cramped. About 10 students can fit comfortably." An unexpectedly large class is a problem because the classroom can not easily accommodate extra students.

All of the organizations also improvise the materials they use in the class to some degree. Northern, Southern, and Eastern all have a core set of materials or guidelines that are intended to be used as a model for the classes. However, in all three of these cases, the teachers are free, and in some cases required, to draw on supplemental materials for the classes. For example, teachers use materials and activities from a wide variety of 
books, use ideas found on the Internet, and draw on their own personal background and resources to provide the content for just one lesson. Although the community college has somewhat of a more consistent set of materials that they use for each class, "all the instructors will supplement appropriate materials that they find or that they invent, around that common material." Some of the classes at the community college do not have a required text at all, so the teachers piece together the entire curriculum for that course. Teachers at the public school system also improvise materials, basing their lessons on student profiles and interest levels in different topics. They identify the needs of the students, and then "build lessons not only around what they don't know from the text, but what their needs are for general everyday life." No two classes are ever alike.

\section{A Holistic Approach to Teaching ESL}

Northern promotes a holistic approach to teaching English. Although a holistic approach is not directly discussed at the other organizations, most of them do offer services other than English classes for their students. The interviews with both the director and a teacher at Northern show that in addition to offering a wide variety of services to the students, they also teach English holistically. The English teacher stated:

"My belief is you can't really isolate, you have to teach English holistically. All English is applicable in the workplace anywhere. You can't really say here's a discrete group of words or grammar, structures that you'll need when you go to work in a factory, or to a doctor's office. Anything to come into play as far as language, we're just teaching a general English curriculum."

He does not just grind out basic grammatical structures in class. Instead, he tries to teach content that is relevant to their lives. "It's not just teaching English kind of disassociated from their lives, I'm trying to find relevant content...I want to talk about something related to healthcare, something related to their job, or some sort of cultural orientation 
topic to orient them to (the city)." Teaching English must accompany teaching other pertinent information in order to be effective.

Northern also offers a wide array of services that the students can utilize to help them understand and function in their new environment. They provide a cultural orientation class one day a week, job developers, and various information sessions for the students. Furthermore, the ESL classes are offered in the same building where the rest of the staff works. Having all the services in one central location is a valuable and convenient asset for the students, since they are all dealing with many new programs and services. As the director said, "ESL classes are also sort of a social environment, a place to come and socialize or get information. Because the classes are here at the office, it's really nice so they can easily go upstairs and talk with their case manager or job developer. Not all programs are structured that way." Northern aims to give the refugees as many services as possible. The refugees form a social bond with the agency from going to the building nearly everyday. As the teacher said, "We do want them coming here everyday. That way if they need us, or we need them, they're right here. We're all in the same building, and it's an intensive kind of holistic resettlement for them."

The other non-profit organizations did not specifically mention teaching English holistically. They do teach a wide variety of topics in class and offer many services in addition to ESL. For example, Southern teaches information relevant to students' jobs in the horse industry. The non-profit organizations offer other services as a supplement to the life skills and cultural information that students learn in class. For example, Western provides youth after school and summer programs, computer classes, and offers free tax preparation services. Southern has a library, and also provides GED preparation and 
conversation tables for the students. Students use Eastern as an information resource, to find out how to pay their electric bill or how to enroll their children in school. The assistant director of Western summarized the rationale behind a holistic approach to teaching English. "Many people want to learn English, it's just having supports in place that makes it possible. Like, where are the children going to be while they're learning? How do they fit that in with an already busy schedule?"

\section{Teaching a Diverse Clientele}

Many of the ESL program directors emphasized that the origins of the immigrants and refugees they serve vary depending on current global events. One year an organization might work with a large number of Sudanese men, another year there might be an influx of Somali-Bantu women, and the next year they might teach a large number of Russians. Particularly with refugees, but also for immigrants, the native country of the students depends largely on world events and politics. This is especially true for Northern, which works exclusively with resettling refugees.

Many of the organizations also have a constantly changing student population. At Northern, in particular, new refugees arrive on a regular basis, and refugees who have been there for two or three months start working and become more independent. With their refugee populations changing on about a one or two year cycle, staff members and volunteers at Northern have to constantly educate themselves about the changing backgrounds of their students. The department head at the community college feels that the background of their students largely depends on the most recent refugee movement. She stated that "when I first started teaching here, we had lots and lots of Bosnians. 
Those people have now moved out into the community, but we have really all continents, most nationalities."

Every organization except one reported serving a student body from all over the world. Southern is an exception because they serve the mostly Hispanic group of workers at the racetrack. Almost all of their students are from a few Latin American countries. All of the organizations also reported a very diverse age range among the students. Ages range anywhere from eighteen to sixty-five or more, although most students are probably somewhere in their twenties to forties. Most of the organizations reported roughly an equal number of male and female students. Southern is the exception again, since about $70 \%$ or more of the racetrack workers were male. Finally, all the organizations also reported that their students had widely varying educational backgrounds, literacy levels, and English abilities.

\section{Difficulties and Problems with Teaching English as a Second Language}

The organizations in this study reported a wide variety of problems and challenges that arise when trying to teach English as a second language. Some of the challenges are structural in nature, and relate to the way the program is run or the available resources. The other category of problems is related to the students. For example, programs face challenges with attendance and the varying English abilities of the students.

One structural problem involves space issues. The class size at Northern is limited based on the space available in their building. Having an unusually large number of refugee arrivals puts extra stress on the program because the classrooms are not big enough to handle the extra people. One of their classrooms is just a small, converted 
apartment, complete with a small sink and closet. As a result, not all students are able to face the teacher. Similarly, Southern only has one traditional classroom. The other two classes work out of a lobby area and a computer lab. The director summed up this challenge by saying, "it's a good problem to have but a hard problem to solve. We don't have enough space for all of our students."

Another structural problem at Northern is that they constantly have a new stream of refugees coming into the program. Over time, students start going to work orientation classes and practice interview sessions, so they have a lot of students coming in and going out. This is a big challenge for them. Since the populations are constantly changing, "we're always having to learn the cultural differences, expectations, and while the goals of the resettlement program don't change, we have to accommodate different cultures. There's a lot of education that has to go on about different cultures and their expectations and where they're coming from." The changing class composition makes it difficult to follow a formal curriculum.

Southern has some unique structural problems. All of their students make regular trips around the country to follow their trainer to other racetracks. "If the trainer takes their horses and moves somewhere else, then the students leave because they follow their work and don't stay because we're here. They're geared to work." In this case, working is the students' top priority, while learning English is somewhere lower on the list. A similar problem at Southern is that the students tend to change jobs a lot. "They might be working for one trainer one week, and then they're not there anymore. We have to figure out if they're even on the track anymore. We're trying to set up more procedural things that will allow us to catch more of those students." They have a difficult time keeping 
track of students since they move around so much. As a result, they must spend valuable time and resources finding students and determining if they still plan on attending class.

A problem at Western results from their ESL arrangement with the public school system. Since the school system runs their program, they have the problem of trying to stay in contact with students. After they moved into a new, bigger building a few years ago, they felt themselves becoming disconnected from the adult education programming. "Now students can come in and out of this building and never see my face,... and so that is a concern for us sometimes in that students can participate in something in this building and not really know about other opportunities in the building or with the center, or not really understand what the heart of the center is." Since Western has given complete control of the ESL program to the school system, they lose some contact with students and residents. As a result, those students may miss out on valuable services and opportunities.

As a result of their grants with the state of Kentucky, the ESL program at the public school system is faced with the challenge of advancing half of their students to the next class level each year. The only way to prove this advancement is with a certain test score. This is one of their biggest challenges. "We know that students are getting better, but the only documentation that the government will accept is a test score." If they do not meet their enrollment and advancement goals, they could potentially lose future funding. So they are under a lot of pressure to make sure the students gain enough English ability to test into the next level. They also offer a limited number of classes depending on the demand in a given area of the city. They can only maintain a class if twelve to fifteen students attend that class every time it meets. Some of their sites offer 
several different classes because there are enough students in that area. Other sites are too small, and can only offer one class that is often a multi-level class of students with many different levels of English ability.

There are also several problems that deal specifically with the students.

Attendance is a big concern and affects how the teachers teach their classes. Last year, Eastern used both pre- and post-tests to gauge their students' level of English ability. But they "stopped using it because attendance became very random and the people in the classes kept changing. We couldn't really figure out a way to test around the scattered attendance." Scattered, random attendance is a common problem cited at many of the organizations. The exceptions to this are the community college, which enrolls students who pay tuition, and Northern, which requires the refugees to attend ESL class. Similarly, the teacher at Southern feels that teaching is challenging because "a student might be gone for three weeks, depending on his trainer and where his horse is. So that makes it difficult to make sure everybody gets everything that you want them to get." As a result, class lessons are often modified or created on the spot to fit the needs of the students who come to class on any given day.

Another problem is that students of widely differing abilities are often placed in the same class, usually because of space issues. Multi-level classes are the most difficult classes to teach. Eastern teaches two classes per week, "but they're not divided up into skill level, because we don't have a large scale structure in place right now." Eastern does not have enough resources to be able to offer a greater number of classes at different levels for the students. As a result, they often assign an individual tutor to more advanced students, or refer them to another resource. The ESL teacher at Northern also 
commented on how difficult it is to teach to students at different levels in the same class.

He teaches students with very different levels of literacy and formal education. He works around this partly because it is a three hour class. "When I develop the lesson I try to think of the lowest common denominator, trying to get some easy material that we can all work through together. And then I'm trying to come up with some add-ons or some extensions that might be more challenging for the higher level students." From my own experience as a volunteer ESL teacher, it is very difficult to teach so that the weaker students still understand, but the stronger students do not get bored or dominate the class.

The public school system also faces the challenge of teaching students with different abilities. The director discussed some of the learning strategies they utilize in multi-leveled classes. If possible, they use volunteers in multi-level classes to provide additional help to the low level students. However, if volunteers are not available, they have more advanced students serve as peer teachers or peer tutors. They also sometimes structure multi-level classes so they have different activities that cover the same general topic. "You have the same reading, then you ask the (low level) student just to pick out words that they know, but you ask (a more advanced) student to write a long response about what this means to them." These are some of the ways the public school system tries to address the challenge of multi-level classrooms.

A final challenge with the students is that they often have very different educational backgrounds and different levels of literacy in their native language. The higher the students' level of previous education is, "the more they can relate back to their native language...But with the students that are not literate in their own language, even just writing and copying down the sentence that they're learning, that's a job for them to 
do...And it involves students doing more memorization than anything." It is much more difficult for students who do not have reading and writing skills in their native language to learn those same skills in a second language. As one potential solution to this problem, Southern is offering a transitional class for these students that will be taught partly in Spanish. It is intended to help transition them into the regular English-only classes. 


\section{CHAPTER VII \\ DISCUSSION AND CONCLUSIONS}

The present study sought to describe the structure and processes of ESL programs and ascertain the implications for classroom dynamics. Previous studies have primarily focused on student characteristics and specific teaching strategies, and have not examined ESL programs from an organizational perspective. The goal of this research was to examine the structure of ESL programs, and then determine how the structure affects their ESL philosophy, goals, and teaching practices.

There were several limitations to the current study. The initial focus was on Hispanic immigrants and their involvement in ESL programs, given the rapid rise in Hispanic immigration. Examining ESL programs in the context of one large group of students may have made the analysis stronger, but this approach did not appear feasible. With the exception of the Southern program, all the organizations reported teaching to an extremely diverse mix of students from all over the world. Classes were not arranged based on country of origin or background, so it would be difficult to study a specific group of students. As a result, the focus remained on the organizations and how they teach students from all backgrounds.

Another limitation is that the ESL programs in this study are not exhaustive of the programs in the county, although the bigger and more well-known programs were selected. A respondent asked if churches that offer ESL classes were included in the 
study. Due to time constraints and issues of access, it was not possible to locate and include church programs in the study. It was not feasible to interview the coordinators of every ESL program in the area.

The generalizability of this study is also limited. This study tried to describe the structure and organization of a sample of ESL programs in one Kentucky county. It is possible that other Kentucky counties are structured similarly to the one in the present study. Without further research, conclusions can only be drawn about the organizations in the present study. This study did not attempt to evaluate the effectiveness of the ESL programs and how well they taught English to their students. As such, a discussion of how capable the programs are at teaching English is beyond the scope of this study.

There were three expectations of this study. The first expectation was that programs would be segregated and distinct from one another. The literature assumes that ESL programs are highly segregated, but no studies actually affirm this assumption. However, these programs are much more connected and linked than initially expected. As the ESL coordinator at the public schools said, "The ESL community is very tight. We all know each other." All of the organizations utilized the public school system to some degree. The cooperation was as major as letting the school system teach the ESL classes, or relatively minor such as borrowing materials and testing supplies from them. The cooperation between programs, as well as various partnerships within the community, serves as a supplement for inadequate funding and resources.

The extent of cooperation between programs does produce some similarities, but does not provide a great deal of consistency among the ESL programs. Many organizations teach English for specific purposes, some curriculum materials and CASAS 
testing supplies are used at multiple locations, and some students even attend more than one ESL program. However, the frequency and size of the ESL classes is highly variable, as is the curriculum and teaching materials that are used in the classroom.

Based on the expectation that ESL programs would be somewhat isolated, it was also expected that the ESL programs would be largely disorganized and ineffective at teaching English to the students. However, each program in the study had a very specific goal in mind. For the most part, their different teaching strategies and philosophies seemed to work toward achieving their goals. For example, Northern taught life skills and job-related information, and eventually helped find employment for all of their students. Southern also focused on jobs, and reported some success in having students advance in their jobs. At the same time, the more structured approach at the community college seemed to be effective in preparing students for college, since most of their students went on to graduate from the community college or another college. While these organizations have very different structures, goals, and teaching practices, they seem to be able to reasonably teach English based on their goals and the goals of the students.

A second expectation was that the ESL programs would be challenged to teach an extremely diverse clientele. The literature extensively supported this expectation (Buttaro and King 2001; Crandall and Sheppard 2004; Fennelly and Palasz 2003; Shank and Terrill 1995). The findings also indicated that ESL programs must try to teach to a very diverse clientele, who are often placed in multi-level classes. Multi-level classes are simply classes which contain students with a wide variety of English skills and abilities. This was one of the most difficult challenges that organizations reported. Their student 
population was usually in a constant state of flux as students entered and left the program for different reasons. Student demographics are largely out of their control since most programs are voluntary and provide continuous open enrollment of students.

Being able to offer a variety of classes and services to a diverse clientele is largely a structural problem. Few of the organizations were able to provide a significant number of hours of English classes per student. For example, Northern required students to attend class for three hours every morning. However, the students must quit class to go to work within two to three months. Also, their location in a former nursing home limits the amount of space they have available for classrooms. Similarly, the public school system is only able to offer a single class at some locations because there are not enough students to support more classes. Part of the reason it takes immigrants so long to learn English is that they are rarely required to attend class, and have differing levels of motivation to attend (Harper and de Jong 2004). Most of the classes in this study were voluntary. Most students attend class in their spare time, working in class time around their work and family schedules. The community college, which teaches mostly more advanced students, often had students enrolled in three or four classes per semester. So their students were regularly inundated with English classes. Although the public school system offered many classes at different locations, they are voluntary and most students only go a few hours per week.

The final expectation was that new assimilation patterns, featuring a greater acceptance of cultural differences, would lead to services that were strongly clientoriented. A holistic approach to teaching English is one of the best examples of an organization catering to the needs of its clients. These programs recognized that students 
have a wide variety of motivations and goals that affects their willingness to adapt to their new environment. Most organizations support their students' cultural, affective, and motivational needs by offering cultural classes, providing child care services during classes, and providing other services of interest to the students. Several organizations offered classes in GED or citizenship test preparation. This is important because learning English, although a significant achievement, is not enough to enable immigrants and refugees to adapt to their new society. They also have emotional needs while adapting to an unfamiliar culture. Furthermore, a holistic approach is much less coercive to the students than the more traditional model of Anglo-conformity.

The ESL programs in the present study offer classes to a select clientele with limited resources. They are not organized or connected by national guidelines, curriculum, or even a common purpose (Burns 2003; Nolan 2001). A significant theme among the ESL programs in this study was that they were all constantly challenged to find new sources of funding and resources. Most of these organizations utilized teachers with some level of experience, either with teaching in general or with ESL in particular. However, these teachers were almost always part time employees or volunteers with a limited amount of time to dedicate to their classes (Crandall 1993). Much of the funding for these different organizations comes from a varied assortment of grants, fundraising, and in-kind donations. More funding from other sources would definitely help them provide more teachers on a full time basis, greater staff support, and more resources for the students. All the programs could use more funding, and the part time teachers often had little time available outside of the classroom. As a result, the programs often could not provide as many services as they wished. 
One significant shortcoming of the ESL programs arose from the interviews, and should be addressed in future research. In an informal discussion after one of the interviews, a director mentioned that while there were good programs for both the very beginning students and advanced students focused on academics, there were not really any programs that tried to transition students from low to high level English classes. Only one study in the literature review noted the same problem (Crandall and Sheppard 2004). While beginning classes focus on survival skills and employment, and advanced classes focus on academic skills, there are few programs that enable students to transition into these higher level classes.

As an example of the missing transitional programs, the public school system had over one thousand students enrolled in six levels of different classès last year. Almost half of those students were in the two beginning classes, and another third of the students were in the top two classes. The intermediate classes were much smaller. There was "a little bit of a chasm, because it used to be that the middle levels were heavier." From the data, it seems that it is easier to create programs for beginning and advanced students, perhaps because their goals are clearer. What is missing is a mid-level, transitional stage. However, the director at the public school system did mention one attempt they were making at addressing this gap. "There was a real call from the community. There was a gap between Adult Education and college, and so we developed a new curriculum to go between that. That is a set curriculum because it's targeted on academic listening and academic writing." The effectiveness of the transitional curriculum is outside the scope of the present study. 
Overall, the organizations in the current study seem to achieve their short-term goals fairly well, including preparing students for employment, teaching basic communication skills, and preparing them for other classes. By focusing on the needs of the students and adapting the curriculum towards those students, they are able to achieve some degree of teaching success. However, every organization in this study was very limited in the programs they could offer, largely because funding and resources were so limited. Even the ESL program at the public school system, which was by far the biggest adult ESL program in the area, was unable to offer all the services they wanted to because they were limited by their grant funding.

A big question left unanswered by the present study is, how effective are the ESL programs at these organizations? This study did not attempt to answer this question. While the directors and teachers did provide some idea of the outcomes of the students, it is not immediately clear how effective the different programs are at teaching English. Undoubtedly, all the programs are beneficial, to different degrees, to the students who attend these classes. Further research should be conducted that investigates the actual effectiveness of these different ESL programs, and the degree to which the organizations achieve their stated goals. This study was also limited to examining ESL programs for adults. There exists a large body of literature on ESL programs for children. It would be beneficial to explore how ESL programs for children are related or comparable to ESL programs for adults. Is one more beneficial to the students than the other? Are there any similarities between the structure and processes of programs for children and adults?

Finally, given the changing patterns of immigration and assimilation, and the increasing visibility of immigrant groups in the national media, it is more important than 
ever to examine the U.S.' relationship with its immigrants and refugees. Perhaps there has not been a national ESL policy because immigration issues have not been at the forefront of U.S. politics. As recent debates on immigration demonstrate, this is quickly changing. As a result, a close examination of how and why we offer services to immigrants is necessary, including English as a second language programs. This study is just an initial attempt to describe the structure and processes of ESL programs in one county, which few other studies have attempted. Much more research needs to be conducted to establish the general structure and organization of ESL programs throughout the entire country. 


\section{REFERENCES}

Aguirre, Jr., Adalberto and Jonathan H. Turner. 2004. American Ethnicity: The Dynamics and Consequences of Discrimination, $4^{\text {th }}$ Edition. New York: McGraw-Hill.

Alba, Richard. 1999. "Immigration and the American Realities of Assimilation and Multiculturalism." Sociological Forum 14:3-25.

Alba, Richard and Victor Nee. 2003. Remaking the American Mainstream: Assimilation and Contemporary Immigration. Cambridge, Mass.: Harvard University Press.

Alba, Richard and Victor Nee. 1997. "Rethinking Assimilation Theory for a New Era of Immigration." The International Migration Review 31:826-74.

Arias, Elizabeth. 2001 "Change in Nuptiality Patterns Among Cuban Americans: Evidence of Cultural and Structural Assimilation?" The International Migration Review 35:525-56.

Babbie, Earl R. 2004. The Practice of Social Research, $10^{\text {th }}$ Edition. Belmont, CA: Wadsworth Publishing.

Berry, Rita Shuk Yin and Marion Williams. 2004. "In at the Deep End: Difficulties Experienced by Hong Kong Chinese ESL Learners at an Independent School in The United Kingdom." Journal of Language and Social Psychology 23(1):118134.

Bowles, Samuel and Herbert Gintis. 1976. Schooling in Capitalist America: Educational Reform and the Contradictions of Economic Life. New York: Basic Books.

Burns, Anne. 2003. "ESL Curriculum Development in Australia: Recent Trends and Debates." Regional Language Center Journal 34(3):261-283.

Buttaro, Lucia. 2001. "Understanding Adult ESL Learners: Multiple Dimensions of Learning and Adjustments Among Hispanic Women." Adult Basic Education 11(1):40-60. 
Buttaro, Lucia and Kathleen P. King. 2001. "Understanding Adult ESL Learners: Multiple Dimensions of Learning and Adjustments Among Hispanic Women." Adult Basic Education 11(1):40-60.

Cornell, Stephen and Douglas Hartmann. 1998. Ethnicity and Race: Making Identities in a Changing World. Thousand Oaks, CA: Pine Forge Press.

Crandall, JoAnn. 1993. "Professionalism and Professionalization of Adult ESL Literacy." TESOL Quarterly 27:497-515.

Crandall, JoAnn and Ken Sheppard. 2004. "Adult ESL and the Community College." Working Paper for the Council for Advancement of Adult Literacy.

Elmeroth, Elisabeth. 2003. "From Refugee Camp to Solitary Confinement: Illiterate Adults Learn Swedish as a Second Language." Scandinavian Journal of Educational Research 47(4):431-449.

Ernst-Slavit, Gisela, Monica Moore, and Carol Maloney. 2002. "Changing Lives: Teaching English and Literature to ESL Students." Journal of Adolescent and Adult Literacy 46(2):116-128.

Feagin, Joe R. and Clairece Booher Feagin. 2003. Racial and Ethnic Relations, $7^{\text {th }}$ Edition. New Jersey: Prentice Hall.

Fennelly, Katherine and Nicole Palasz. 2003. "English Language Proficiency of Immigrants and Refugees in the Twin Cities Metropolitan Area." International Migration 41,5:93-123.

Gillespie, Marilyn K. 1994 "Rationales for Adult Native Language Literacy and Directions for Research." National Center on Adult Literacy Technical Report TR94-03. http://www.literacyonline.org/products/ncal/pdf/TR9403.pdf.

Grassi, Elizabeth, Daniel Hanley, and Daniel Liston. 2004. "Service-Learning: An Innovative Approach for Second Language Learners." Journal of Experiential Education 27(1):87-110.

Harper, Candace and Ester de Jong. 2004. "Misconceptions About Teaching EnglishLanguage Learners." Journal of Adolescent and Adult Literacy 48(2):152-162.

Heisler, Barbara Schmitter. 1992. "The Future of Immigrant Incorporation: Which Models? Which Concepts?" International Migration Review 26(2):623-645.

Holt, Grace Massey. 1995. "Teaching Low-Level Adult ESL Learners." Center for Adult English Language Acquisition. http://www.cal.org/caela/esl\%5Fresources/ digests/HOLT.html. 
Hubenthal, Wendy. 2004. "Older Russian Immigrants' Experiences in Learning English: Motivation, Methods, and Barriers." Adult Basic Education 14(2):104-26.

Jeynes, William H. 2004. "Immigration in the United States and the Golden Years of Education: Was Ravitch Right?" Educational Studies 35(3):248-270.

Kim, Jungkang. 2005. "A Community Within the Classroom: Dialogue Journal Writing Of Adult ESL Learners." Adult Basic Education 15(1):21-32.

Kim, Kwang, Mary Collins, and Edith McArthur. 1997. "Participation of Adults in English as a Second Language Classes: 1994-95." National Center for Education Statistics, U.S. Department of Education.

Kim, Young Yun. 2001. Becoming Intercultural: An Integrative Theory of Communication and Cross-Cultural Adaptation. Thousand Oaks, CA: Sage Publications, Inc.

Loori, Ali A. 2005. "Multiple Intelligences: A Comparative Study Between the Preferences of Males and Females." Social Behavior and Personality 33(1):7788.

McCracken, Grant. 1988. The Long Interview. Newbury Park, CA: Sage Publications.

Miller, Paul Chamness and Hidehiro Endo. 2004. "Understanding and Meeting the Needs of ESL Students." Phi Delta Kappan 85(10):786-791.

Mohan, Bernard. 1986. Language and Content. Reading, MA: Addison Wesley.

Mori, Setsuko. 2004. "Significant Motivational Predictors of the Amount of Reading by EFL Learners in Japan." Regional Language Centre Journal 35(1):63-81.

Nolan, Robert E. 2001. "The Power of Theory in the Administration of ESL Programs." Adult Basic Education 11(1):3-16.

Orem, Richard A. 2001. "Journal Writing in Adult ESL: Improving Practice Through Reflective Writing." New Directions for Adult and Continuing Education 90:6977.

Oropesa, R. S. and Nancy S. Landale. 1997. "Immigrant Legacies: Ethnicity, Generation, and Children's Familial and Economic Lives." Social Science Quarterly 78(2):399-416.

Pally, Marcia. 1998. "Film Studies Drive Literacy Development for ESL University Students." Journal of Adolescent and Adult Literacy 41(8):620-628. 
Paredes, Sara Micaela. 2000. "How Proposition 227 Influences the Language Dynamics of a First- and Second-Grade Mathematics Lesson." Bilingual Research Journal 24(1/2):179-198.

Parrillo, Vincent N. 2005. Diversity in America, $2^{\text {nd }}$ Edition. Thousand Oaks, CA: Pine Forge Press.

Pennycook, Alastair. 1999. "Introduction: Critical Approaches to TESOL." TESOL Quarterly 33:329-348.

Portes, Alejandro. 1995. "Children of Immigrants: Segmented Assimilation and Its Determinants." Pp. 248-79 in The Economic Sociology of Immigration: Essays on Networks, Ethnicity, and Entrepreneurship, edited by Alejandro Portes. New York: Russell Sage Foundation.

Portes, Alejandro and Rubén G. Rumbaut. 2001. Legacies: The Story of the Immigrant Second Generation. Berkeley: University of California Press.

Rolstad, Kellie, Kate Mahoney, and Gene V. Glass. 2005. "The Big Picture: A MetaAnalysis of Program Effectiveness Research on English Language Learners." Educational Policy 19(4):572-594.

Rossell, Christine. 2005. "Teaching English Through English." Educational Leadership 62(4):32-36.

Rubin, Herbert J. and Irene S. Rubin. 1995. Qualitative Interviewing: The Art of Hearing Data. Thousand Oaks, CA: Sage Publications.

Rumbaut, Ruben G. 1994. "Origins and Destinies: Immigration to the United States Since World War II.” Sociological Forum 9(4):583-621.

Schaefer, Richard T. 2005. Race and Ethnicity in the United States, $3^{\text {rd }}$ Edition. New Jersey: Pearson Education, Inc.

Shank, Cathy C. and Lynda R. Terrill. 1995. "Teaching Multilevel Adult ESL Classes." Center for Adult English Language Acquisition. http://www.cal.org/caela/es1\%5 Fresources/digests/SHANK.html.

Skilton-Sylvester, Ellen and Maria S. Carlo. 1998 '"I Want To Learn English': Examining the Goals And Motivations of Adult ESL Students in Three Philadelphia Learning Sites." National Center on Adult Literacy Technical Report TR98-08.

South, Scott J., Kyle Crowder, and Erick Chavez. 2005. "Migration and Spatial Assimilation Among U.S. Latinos: Classical Versus Segmented Trajectories." Demography 42(3):497-521. 
Walter, Pierre. 1998. "Southeast Asian Refugees' Strategies for Meeting English

Literacy Demands: An Exploratory Study." Adult Basic Education 8(3):123-138.

Warriner, Doris S. 2004. "Multiple Literacies and Identities: The Experiences of Two Women Refugees." Women's Studies Quarterly 32(1/2):179-195.

Waters, Mary C. and Tomas R. Jimenez. 2005. "Assessing Immigrant Assimilation: New Empirical and Theoretical Challenges." Annual Review of Sociology 31:105-25.

Weinstein-Shr, Gail. 1993. "Growing Old in America: Learning English Literacy in Later Years." Center for Adult English Language Acquisition. http://www.cal.org/caela/es1\%5Fresources/digests/grow.html.

Wildsmith, Elizabeth. 2004. "Race/Ethnic Differences in Female Headship: Exploring the Assumptions of Assimilation Theory." Social Science Quarterly 85:89-106.

Wrigley, Heide Spruck and Julie Strawn. 2003. "A Chance to Earn, A Chance to Learn: Linking Employment and English Training For Immigrants and Refugees New to English." Illinois State Board of Education. http://www.isbe.net/bilingual/ pdfs/employimmigrants.pdf.

Zhou, Min. 1997. "Segmented Assimilation: Issues, Controversies, and Recent Research on the New Second Generation." The International Migration Review 31:9751008.

Zhou, Min. 2004. "Assimilation, the Asian Way.” Pp. 139-153 in Reinventing the Melting Pot, edited by Tamar Jacoby. New York: Basic Books. 


\section{APPENDIX A}

\section{INTERVIEW QUESTIONS - ESL COORDINATOR}

I. Questions About the Organization

A. Information about the Participant

1. Job title

2. Length of time in current position

3. Other experience similar to current position

B. The Structure of the Organization

1. What is your program philosophy?

a. Was this philosophy influenced by any other sources? If so, how?

b. As an organization, what is your goal in teaching English as a second language?

i. How was this goal developed?

2. How many paid employees work with the English as a Second Language (ESL) Program?

a. What qualifications are required for your paid ESL employees?

b. What positions do these employees occupy? (i.e. teachers, etc.)

3. In addition to the paid employees, how many other teachers or volunteers work with the ESL program?

a. What qualifications are required for volunteers to work with your ESL program?

b. How do you recruit volunteers?

c. What are the roles of volunteers in your ESL program? 
4. How is your organization connected with other organizations?

For Example:

a. Do you share a funding source with any other organizations?

b. Do you cooperate/partner with other organizations or programs?

c. Do you regularly report to another organization that oversees your operations?

d. What influence does the board of directors have on your program?

5. How is your organization funded?

a. How big is your budget?

b. How is your funding divided up within your ESL program?

c. Besides your budget, what other resources does your organization utilize?

C. The Processes of the Organization

1. Describe the classes.

a. How often and at what times and dates do they meet?

b. What curriculum do you use for the classes?

i. Is the curriculum the same for all classes? If so, who decides what the curriculum should be?

ii. How are your organizational philosophy and goals reflected in the curriculum or teaching materials?

c. Describe the lesson materials and activities in as much detail as possible.

d. Do you have any copies or examples of materials that I can look at or borrow?

e. Do you test students to measure their progress? Is this testing standardized? Where did the tests originate?

2. How are the policies/guidelines set for the ESL classes?

D. Effectiveness of the Organization

1. What are the characteristics of the students in your classes?

a. How many students do you have? 
b. How old do they tend to be?

c. What is the proportion of men to women?

d. What are their countries of origin?

e. What is their level of English ability upon entry into the program?

ii. How do you measure their initial English ability? Tests?

f. How long do students tend to remain in the ESL classes?

g. What is their level of literacy in their native language?

i. How does this affect their performance in English classes?

2. Can you comment on why students attend these ESL classes? What are their motivations and goals?

a. How are students monitored or tested during their time in the program?

b. What are the outcomes for the students? What do they do once they stop attending classes?

c. Do you conduct follow-ups with any students once they leave the program?

d. How are the ESL classes beneficial to the students?

3. Do you have anything else to add? 


\section{APPENDIX B}

\section{INTERVIEW QUESTIONS - TEACHER}

I. Questions about the Classes
A. Information about the participant

1. Job Title

2. Are you a paid employee or a volunteer?

3. Length of time in current position

4. Other experience similar to current position

5. What qualifications did you have to meet to teach/volunteer with this program?

6. What interests you about teaching ESL?

B. Information About the Classroom Environment

1. Describe the physical layout of the classroom in which you teach in as much detail as possible.

2. How do students situate themselves within the room? For example, do people with similar backgrounds cluster together?

3. What equipment do you use in the classrooms (chalkboard/projector/etc.)?

4. Describe the atmosphere during classes? (friendly/stressful/loud/etc.)

C. Processes of the Organization

1. Description of classes.

a. How often and at what times and days do your classes meet?

b. Describe your lesson materials and activities in as much detail as possible. 
c. Is your curriculum the same as that used in other classes here? Where do the curriculum/materials come from?

d. What strategies do you use to get students to participate?

e. What teaching strategies do you use to teach different concepts?

f. Do you have any copies or examples of materials that I can look at or borrow?

g. Do you test students to measure their progress?

i. If so, what are the tests like? Are they standardized?

h. How often do the students have English homework to complete before class?

i. What activities do you assign for them to complete outside of class?

2. What are the characteristics of the students in your classes?

a. How many students do you have?

b. How old do they tend to be?

c. What is the proportion of men to women?

d. What are their countries of origin?

e. What is their level of English ability upon entry into the program?

i. How do you know?

f. What is their level of literacy in their native language?

i. How do you know?

g. How long do students tend to attend the ESL classes?

h. What are the student's attendance records like?

i. How does this affect their performance in English classes?

3. Can you comment on why students attend these ESL classes? What are their motivations and goals? 
a. How are the students monitored or tested during their time in the program?

b. What are the outcomes for the students? What happens to them once they stop attending classes?

c. How are the ESL classes beneficial to the students?

4. Do you have anything else to add? 
Summary Description and Analysis of ESL Programs in the Present Study

\begin{tabular}{|c|c|c|c|c|c|}
\hline $\begin{array}{l}\text { Organization } \\
\text { Name }\end{array}$ & $\begin{array}{l}\text { Type of } \\
\text { Organization }\end{array}$ & $\begin{array}{l}\text { Number and Type of } \\
\text { Employees }\end{array}$ & ESL Funding & $\begin{array}{l}\text { Goals of the } \\
\text { ESL Program }\end{array}$ & $\begin{array}{l}\text { Teaching } \\
\text { Philosophy }\end{array}$ \\
\hline Northern & $\begin{array}{l}\text { Refugee } \\
\text { Resettlement } \\
\text { Agency }\end{array}$ & $\begin{array}{l}5 \text { paid, part-time } \\
\text { employees }\end{array}$ & $\begin{array}{l}\text { Grants, donations, and } \\
\text { State Department; } \\
\text { Budget }=\$ 200,000\end{array}$ & Survival English & $\begin{array}{l}\text { Teacher } \\
\text { Driven }\end{array}$ \\
\hline Southern & $\begin{array}{l}\text { Education } \\
\text { Center at a } \\
\text { Horse } \\
\text { Racetrack }\end{array}$ & $\begin{array}{l}1 \text { full-time, } 3 \text { part- } \\
\text { time, and } 2 \\
\text { Americorps VISTA } \\
\text { workers }\end{array}$ & $\begin{array}{l}\text { Grants, donations, and } \\
\text { foundations; } \\
\text { Budget }=\$ 150,000\end{array}$ & Survival English & $\begin{array}{l}\text { Teacher } \\
\text { Driven }\end{array}$ \\
\hline Eastern & $\begin{array}{l}\text { Community } \\
\text { Center }\end{array}$ & $\begin{array}{l}1 \text { Americorps } \\
\text { VISTA worker }\end{array}$ & $\begin{array}{l}\text { Primarily donations; } \\
\text { Budget }=\$ 1,000\end{array}$ & $\begin{array}{l}\text { Communication, } \\
\text { betterment of the } \\
\text { students' lives }\end{array}$ & $\begin{array}{l}\text { Teacher } \\
\text { Driven }\end{array}$ \\
\hline Western & $\begin{array}{l}\text { Community } \\
\text { Center }\end{array}$ & $\begin{array}{l}4 \text { paid employees at } \\
\text { the center }\end{array}$ & $\begin{array}{l}\text { Classes offered } \\
\text { through Public School } \\
\text { System }\end{array}$ & $\begin{array}{l}\text { Communication, } \\
\text { betterment of the } \\
\text { students' lives }\end{array}$ & $\begin{array}{l}\text { Teacher } \\
\text { Driven }\end{array}$ \\
\hline $\begin{array}{l}\text { The } \\
\text { Community } \\
\text { College }\end{array}$ & $\begin{array}{l}\text { Community } \\
\text { College }\end{array}$ & $\begin{array}{l}3 \text { full-time and } 10- \\
12 \text { part-time teachers }\end{array}$ & $\begin{array}{l}\text { State revenues and } \\
\text { student tuition; } \\
\text { Budget = Not } \\
\text { Reported }\end{array}$ & $\begin{array}{l}\text { Academic } \\
\text { Achievement }\end{array}$ & $\begin{array}{l}\text { Curriculum } \\
\text { Driven }\end{array}$ \\
\hline $\begin{array}{l}\text { The Public } \\
\text { School } \\
\text { System }\end{array}$ & $\begin{array}{l}\text { Adult } \\
\text { Education } \\
\text { Department at } \\
\text { the Public } \\
\text { School System }\end{array}$ & 25 paid employees & $\begin{array}{l}\text { Federal and state } \\
\text { grants }\end{array}$ & $\begin{array}{l}\text { Communication, } \\
\text { betterment of the } \\
\text { students' lives }\end{array}$ & $\begin{array}{l}\text { Common } \\
\text { resources } \\
\text { and teacher } \\
\text { autonomy }\end{array}$ \\
\hline
\end{tabular}




\section{CURRICULUM VITAE}

Korey McMurtrey

Department of Sociology

115 Lutz Hall, University of Louisville

Louisville, KY 40208
Prepared: February 2006

Phone: (606) 584-6187

Email: koreymcmurtrey@hotmail.com

\section{Education}

M.A. Candidate, Sociology, University of Louisville, Louisville, KY. (August 2004Present)

B.A., Sociology, Transylvania University, Lexington, KY. (May 2004)

\section{Teaching Experience}

Graduate Teaching Assistant, Department of Sociology, University of Louisville, Louisville, KY. Helped teach SOC 210 - Race in the U.S., with Dr. Clarence Talley. (August 2005-Present).

Lectured on the topic of "Discrimination" in SOC 210 - Race in the U.S., University of Louisville. (March 8, 2006)

\section{Research Experience}

Research Assistant, Transylvania University. Worked with Dr. Brian L. Rich to analyze focus group data about the needs of the Hispanic community in Lexington, Ky. (April 2003-May 2004)

\section{Work in Progress}

"Immigration, Assimilation, and Language: A Case Study of ESL Programs in Louisville, KY." This is my Master's thesis project.

\section{Awards and Honors}

Graduate Teaching Assistantship, Department of Sociology, University of Louisville. (January 2005 - Present) 
William T. Young Scholarship, Transylvania University. Provided full tuition to Transylvania University for four years. (September 2000 - May 2004)

\section{Other Experience}

Internship at Kentucky Refugee Ministries (KRM). This is part of a project for my Voluntarism class, SOC 550. I am helping KRM develop lesson plans for ESL classes that utilize computers and the Internet. (February 2006-Present)

\section{Professional Activities}

Member - Alpha Kappa Delta, Sociology Honorary

Omicron Delta Kappa, Leadership Honorary 